University of South Carolina

Scholar Commons

Theses and Dissertations

2018

Matrix Stiffness Modulates Mesenchymal Stem Cell Sensitivity to Geometric Asymmetry Signals

Maria Eugenia Piroli

University of South Carolina

Follow this and additional works at: https://scholarcommons.sc.edu/etd

Part of the Biomedical Engineering and Bioengineering Commons

Recommended Citation

Piroli, M.(2018). Matrix Stiffness Modulates Mesenchymal Stem Cell Sensitivity to Geometric Asymmetry Signals. (Doctoral dissertation). Retrieved from https://scholarcommons.sc.edu/etd/4503

This Open Access Dissertation is brought to you by Scholar Commons. It has been accepted for inclusion in Theses and Dissertations by an authorized administrator of Scholar Commons. For more information, please contact digres@mailbox.sc.edu. 


\title{
MATRIX STIFFNESS MODULATES MESENCHYMAL STEM CELL SENSITIVITY TO GEOMETRIC ASYMMETRY SIGNALS
}

\author{
by \\ Maria Eugenia Piroli \\ Bachelor of Science \\ University of South Carolina, 2015
}

\begin{abstract}
Submitted in Partial Fulfillment of the Requirements
For the Degree of Master of Science in

Biomedical Engineering

College of Engineering and Computing

University of South Carolina
\end{abstract}

2018

Accepted by:

Ehsan Jabbarzadeh, Director of Thesis

Tarek Shazly, Reader

Cheryl L. Addy, Vice Provost and Dean of the Graduate School 
(C) Copyright by Maria Eugenia Piroli, 2018 All Rights Reserved. 


\section{ACKNOWLEDGEMENTS}

I would like to thank everyone who has supported me in all my endeavors. I especially want to thank my family for always being there for me and encouraging me to do my best. This would not have been possible without them.

I am grateful for my advisor, Ehsan Jabbarzadeh, who pushed me to pursue this degree and believed in me. I also would like to thank my lab members Maria Yanez, Wesley Taylor and Sara Eslambolchi for helping me solve problems along the way. I would also like to thank previous lab members Katy Rutledge and especially Greg Harris

for mentoring me as an undergraduate student and helping me troubleshoot from hundreds of miles away. 


\begin{abstract}
Human stem cells hold significant potential for the treatment of various diseases. However, their use as a therapy is hampered by the limited understanding of the mechanisms by which stem cells respond to environmental stimuli. Efforts to understand extracellular biophysical cues have demonstrated the critical roles of geometric and mechanical signals in determining the fate of stem cells. The goal of this study was to explore the interplay between cell polarity and matrix stiffness in stem cell lineage specification. We hypothesize that confining cells to asymmetric extracellular matrix (ECM) islands will impart polarity at a single-cell level and result in polarity signals that will interact with mechanical signals to define the lineage of stem cells. To test these hypotheses, we employed microcontact printing to create patterned symmetric and asymmetric hydrogel islands of soft and hard surface stiffness. Human mesenchymal stem cells (hMSCs) were confined to these islands at the single-cell level and cultured in differentiation media to differentiate along adipogenic or osteogenic routes. Our results established that cell polarity defines the lineage specification of hMSCs only on islands with low stiffness. Insight gained from this study provides a rational basis for designing stem cell cultures to enhance tissue engineering and regenerative medicine strategies.
\end{abstract}




\section{TABLE OF CONTENTS}

ACKNOWLEDGEMENTS ............................................................................... iii

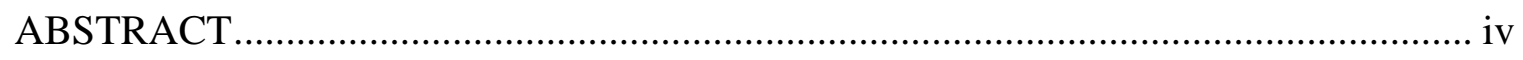

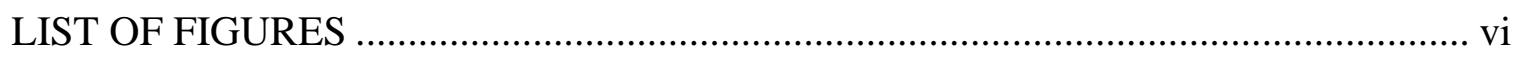

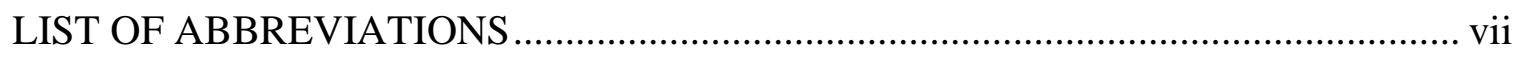

CHAPTER 1: CELL POLARITY AS A PHYSIOLOGICAL

MODULATOR OF CELL FATE ......................................................................... 1

CHAPTER 2: THE ROLE OF CELL POLARITY AND MATRIX

STIFFNESS ON STEM CELL BEHAVIOR ...........................................................19

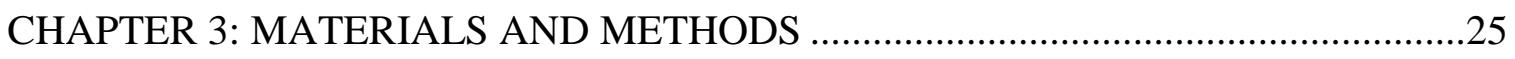

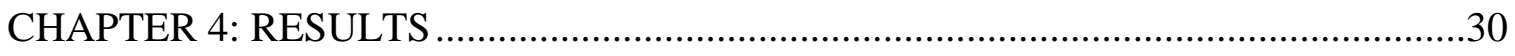

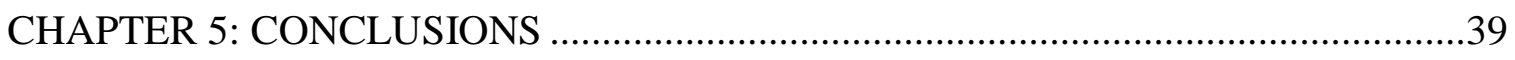

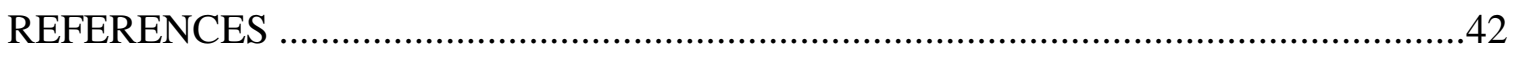

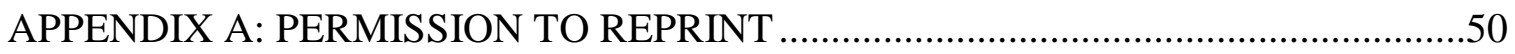




\section{LIST OF FIGURES}

Figure 1.1: Cell polarity is important for cell function .....................................................

Figure 1.2: Cell divisions are controlled by internal and external signals ........................5

Figure 2.1: Schematic of the effects of matrix elasticity and cell asymmetry on mesenchymal stem cell lineage.................................................................24

Figure 3.1: Schematic of micropatterned hydrogel process.......................................26

Figure 4.1: Cell density and matrix stiffness affect hMSC differentiation ......................31

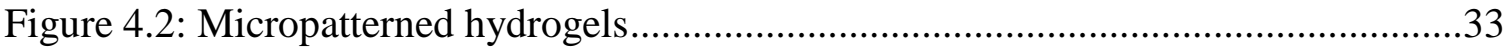

Figure 4.3: hMSCs adopt the shape of the underlying hydrogel patterns .........................34

Figure 4.4: Asymmetry and matrix elasticity both play a role in hMSC lineage commitment 


\section{LIST OF ABBREVIATIONS}

3D.

Three dimensional

ANOVA

Analysis of Variance

APC

Antigen Presenting Cell

aPKC

Atypical Protein Kinase C

BSA. Bovine Serum Albumin

Cdc42 Cell division control protein 42 homolog

DAPI 4',6-diamidino-2-phenylindole

Dlg. Discs Large Protein

ECM Extracellular Matrix

EMT Endothelial-to-Mesenchymal Transition

FBS Fetal Bovine Serum

FITC .Fluorescein Isothiocyanate

GMC Ganglion Mother Cell

GPSM2. G-protein Signaling Modulator 2 
hESC Human Embryonic Stem Cells

hMSC Human Mesenchymal Stem Cells

HSC Hematopoietic Stem Cells

HUVEC Human Umbilical Vein Endothelial Cells

INF- $\gamma \mathrm{R}$ Interferon Gamma Receptor

$\mathrm{kPa}$. Kilopascal

LGN GPSM2 Protein

MTOC Microtubule Organizing Center

NuMA Nuclear Mitotic Apparatus Protein

Par Partition deficient protein

PBS Phosphate Buffered Saline

PEG Polyethylene Glycol

PEG-DA. Polyethylene Glycol-Diacrylate

PKC Protein Kinase C

$\operatorname{Rac} 1$ Ras-related C3 botulinum toxin substrate 1

RhoA Ras homolog gene family, member A

ROCK Rho-associated Protein Kinase 


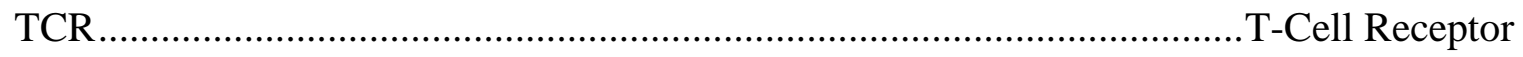

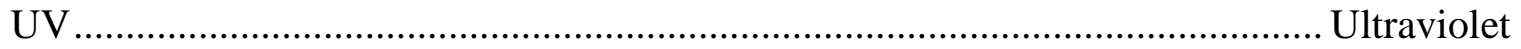




\title{
CHAPTER 1
}

\section{CELL POLARITY AS A PHYSIOLOGICAL MODULATOR OF CELL}

\begin{abstract}
FATE
Polarization, defined as the asymmetric distribution of proteins, organelles and cytoplasm, occurs in many forms. ${ }^{[1]}$ The most commonly known is the apical-basal polarity of epithelial cells. However, there also exists the front-to-back polarity of migrating cells and planar cell polarity, which organizes and polarizes the cells found in one plane of tissue. ${ }^{[2,3]}$ The mechanisms by which cells polarize have been studied in a wide range of organisms and appear to be evolutionarily conserved. ${ }^{[4]}$ However, there are various pathways for each type of polarity and each requires many signaling molecules. ${ }^{[5}$, 6]

The polarization of cells was a critical event in evolutionary biology. For singlecelled organisms such as the budding yeast, polarization is the mechanism by which reproduction occurs. ${ }^{[1]}$ For slightly more complex organisms such as C. elegans and Drosophila, polarization results in the development and organization of different body parts, including the nervous system and wing organization. ${ }^{[6,7]}$ Without polarization, complex organisms with a multitude of cell types would not exist, migration of cells would be impossible, and cells such as epithelial cells would not be able to properly perform their functions. ${ }^{[8]}$
\end{abstract}


We examine the different ways cell polarization is involved in development, homeostasis, and disease. We discuss how microfabrication techniques have allowed for systematic studies of cell polarization and consider the future work needed to improve these techniques.

\subsection{POLARIZATION AND CELL FUNCTION}

The morphology of the cell is optimized to fulfill its function, Figure 1.1. ${ }^{[1]}$ Cells that create compartments such as epithelia must be polarized to keep the contents in their

corresponding partition. ${ }^{[9,10]}$ Epithelial cells can have both apical-basal polarity that allow specialized trafficking of solutes and planar polarity for proper organogenesis. ${ }^{[6]}$ The apical-basal polarity is a result of cell-cell and cell-extracellular matrix (ECM) interactions. Tight junctions between cells prevent proteins and ions from flowing freely between the apical and basal sides, effectively creating a barrier to prevent unwanted material from entering the body. ${ }^{[11]}$ The development and maintenance of polarity is a result of multiple signals from polarity proteins, E-Cadherin and contact with the ECM. These signals organize the cytoskeleton and the organelle localization. Loss of these signals results in differentiation from epithelial to mesenchymal cell type and front-toback polarization. ${ }^{[11]}$

Planar cell polarization is more complex since it is not a direct result of cell-cell contact, but rather positioning of the cell with respect to the organism's body axes. ${ }^{[6]}$ This type of polarity is responsible for the organization of feathers on a bird or the orientation of a fly's wing. Disruption of this type of polarity can result in improper development of the eye or the inner ear resulting in blindness or deafness. ${ }^{[6]}$ 


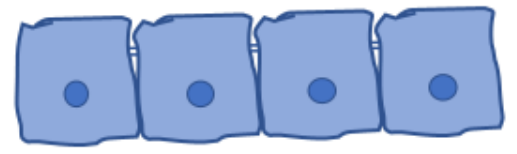

Apical-Basal Polarity of Epithelial Cells

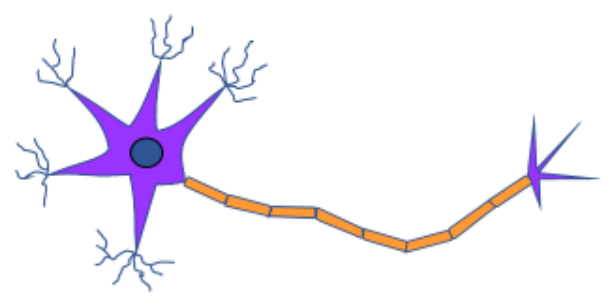

Neurons polarize to send signals from their dendrites down their axon to the synaptic clefts

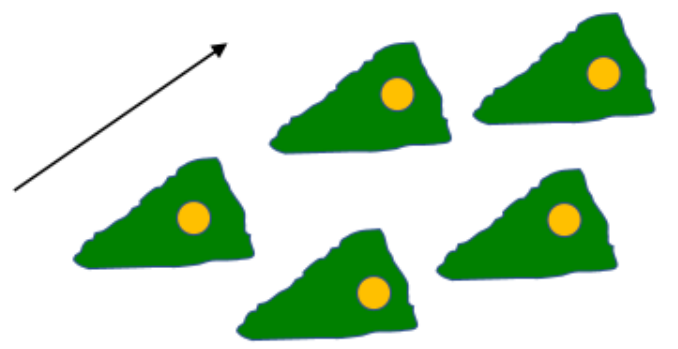

Migrating Mesenchymal Cells Front-to-Back Polarity

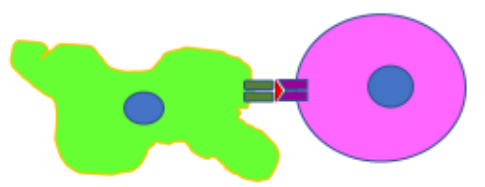

Dendritic cells presenting antigen polarize naïve T cells into cytotoxic $T$ cells or memory T cells

Figure 1.1: Cell polarity is important for cell function. Epithelial cells have apical-basal polarity to provide a barrier function for pathogens. Cell migration requires front-to-back polarity that determines cytoskeletal organization to allow the cell to adhere to the extracellular matrix and detach. Polarity is also required for neurons to perform their task of propagating action potentials and sending messages from the central nervous system to distant body parts. 
This shows that polarity plays a large role in cell function and lack of polarization can have dire consequences to the organism.

Neurons must also be polarized to serve their function of propagating signals to distant parts of the body. ${ }^{[1]}$ Neuronal development in vitro begins with the spreading of small filopodia that grow into small neurites. One of these neurites is selected to become the axon and begins to grow more quickly than the others. Finally, the remaining neurites become dendrites and polarize. ${ }^{[12]}$ The process is slightly different in vivo but all neurons require polarization to function. The polarization is a result of signaling from various secreted factors and the formation of complexes such as Par6-Par3-aPKC (important in asymmetric division and development of the Drosophila nervous system). ${ }^{[12]}$ Other important factors for neuronal polarity include Cell division control homolog 42 (Cdc42), Ras homolog gene family, member A (RhoA) and Ras-related C3 botulinum toxin substrate 1 (Rac1). ${ }^{[13]}$ These factors highlight the importance of the cytoskeleton in polarization of cells and establishment of cell processes such as the axon and dendrites.

\subsection{POLARIZATION IN ASYMMETRIC DIVISION AND DEVELOPMENT}

The phenomenon of asymmetric cell division was observed and recorded by Edwin Conklin in 1905 in the developing embryo of ascidians. ${ }^{[14]}$ Other organisms have since been studied, in particular Drosophila melanogaster and C. elegans, and have elucidated two mechanisms of asymmetric cell division in development. ${ }^{[15]}$ In the intrinsic mechanism, polarization of regulators within the cell causes an uneven distribution of proteins during mitosis resulting in daughter cells with different internal signals leading to differing fates between the daughter cells, Figure 1.2. The extrinsic mechanism relies on cues from the niche, and asymmetric division occurs when the cell 
Symmetric Division

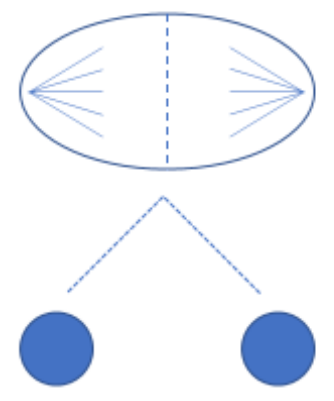

Asymmetric Division

Intrinsic Mechanism
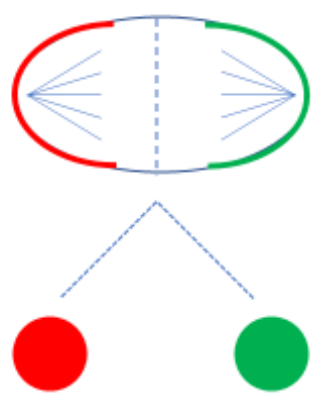

Asymmetric Division

Extrinsic Mechanism

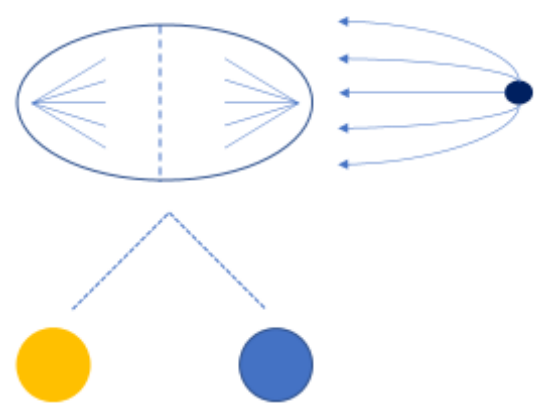

Figure 1.2: Cell divisions are controlled by internal and external signals. Symmetric divisions (on the left) have equal internal and external signals. Asymmetric divisions have two mechanisms. The intrinsic mechanism results in unequal distribution of proteins within the cell (Center). While the extrinsic mechanism is a result of external signals received by only one of the daughter cells, resulting in different daughter cell fates. 
divides perpendicular to the niche resulting in one daughter cell that is proximal and the other daughter cell distal to the niche. ${ }^{[16]}$ In Drosophila, the intrinsic mechanism is used in the development of the nervous system. Here, asymmetric divisions of neuroblasts give rise to one neuroblast and one ganglion mother cell (GMC), which then divides into differentiated neurons. The fate of each cell is controlled by the polarized distribution of the protein Numb and the translational inhibitor Brat. ${ }^{[15]}$ These fate determinants polarize the cell by localizing at the basal membrane during mitosis and can only be found in the basal cell after division. The localization of these fate determinants to the basal membrane is thought to occur because of the accumulation of PAR (partition deficient) proteins and atypical protein kinase $\mathrm{C}(\mathrm{aPKC})$ at the apical side. ${ }^{[16]}$ As a result of this protein polarization, the basal cell becomes a GMC while the apical cell remains a neuroblast.

The importance of polarity in asymmetric division has also been confirmed in the development of $C$. elegans. Before fertilization the $C$. elegans oocyte is not polarized, however the fertilization of the egg by the sperm causes a change in the cytoskeletal integrity affecting the cell contractility and polarization of the anterior and posterior PAR proteins. ${ }^{[17-19]}$ After the C. elegans' egg is fertilized and polarized, the first division is asymmetric and results in a larger anterior body and a smaller posterior cell. ${ }^{[20]}$ The development of $C$. elegans is a continued series of asymmetric and symmetric divisions, governed by anterior-posterior polarity, resulting in the generation of the three germinal layers (ectoderm, mesoderm and endoderm). ${ }^{[21,22]}$

Asymmetric cell division is also critical in mammalian development but is not as well understood or studied because of the long cell cycles in mammals. Studies of the 
developing brain of mice show the complex development with changes from symmetric division to asymmetric division throughout the process. ${ }^{[15,23]}$ The symmetric divisions serve to increase the number of progenitor cells while the asymmetric divisions generate one differentiated nerve cell and a radial glia cell (progenitor cell). ${ }^{[24]}$ Neural development occurs in various stages that involve symmetric and asymmetric divisions and migration of progenitor cells to the basal region of the neuroepithelium for terminal differentiation. ${ }^{[16]}$ The molecules that control asymmetric division in Drosophila are conserved in mammals, however their roles as fate determinants has not been established, with some studies indicating that not all conserved determinants play a role or play a different role in asymmetric division in mammals. ${ }^{[16]}$ One determinant, Numb, has been shown to be critical in asymmetric division and subsequent fate specification in both invertebrates and vertebrates. ${ }^{[24]}$ Polarization of Numb into only one of the daughter cells causes that cell to differentiate into a neuron, while the other daughter cell remains a progenitor cell. Further studies are still required to establish the mechanisms and polarization of fate determinants that leads to asymmetric division in neurogenesis and mammalian development.

The importance of asymmetric division in the development of organisms is clear. Organisms use symmetric divisions to clone cells and asymmetric divisions give rise to new cells with different roles. It allows for the development of new cell types while maintaining a pool of progenitor cells. It gives rise to the three germ layers and all cell types found in the organism. Asymmetric division continues throughout the life of the organism and is involved in wound healing and tissue regeneration, adult stem cell differentiation, cancer, and immune responses. ${ }^{[25,26]}$ All of these processes, however, 
would not be possible without the polarization of proteins, such as fate determinants, to induce these asymmetric cell divisions and create cellular diversity.

\subsection{POLARIZATION AND MIGRATION}

Migration of cells can occur as a result of injury, in development, and in disease progression. Microenvironmental cues cause the cell to organize its actin cytoskeleton and begin migration toward the signal. Some specialized cells, such as sperm, are always polarized and have cilia or flagella to help them migrate, while other cells polarize by growing lamellipodia or filopodia in response to a stimulus. ${ }^{[27]}$ The stimulus causes activation of Rho family proteins, which influence the growth and attachment of actin chains. ${ }^{[27]}$ Cell migration can occur as a single cell or a sheet of cells, referred to as collective cell migration. Although the same mechanisms are required for both migration methods, collective cell migration requires synchronization among all the cells to move without disrupting cell-cell contacts. ${ }^{[28]}$

Regardless of migration type, migratory cells all express mesenchymal genes and have front-rear polarity. ${ }^{[11,28]}$ The front leading edge has proteins such as Cdc42, PAR proteins, activated Rac and in some cells the microtubule organizing center (MTOC) while the rear lacks these proteins, preventing the rear from extending protrusions, and resulting in directional migration. ${ }^{[27]}$

\subsection{POLARIZATION AND CANCER}

Cancer is caused by the abnormal overproliferation of cells. This unchecked growth can be caused by a large variety of mutations. ${ }^{[29-31]}$ A contributing factor toward this dysregulation is the mutation of fate determinants or polarity proteins leading to decreased asymmetric division. These mutations prevent asymmetric division from 
occurring but do not stop the cell from cycling and dividing thereby resulting in an increased number of symmetric divisions and an increase in progenitor cells. ${ }^{[32]}$ This increase in progenitor cells increases the amount of differentiated cells resulting in a neoplasm. This explanation agrees with the hypothesis of cancer stem cells which are cells capable of producing all the cell types in a tumor and have stem cell markers such as those found in early progenitor cells that have not differentiated. ${ }^{[15,33]}$ Although the mechanisms of asymmetric division in mammals are poorly understood, studies have focused on the loss of Numb regulation as a possible explanation for cancer propagation as a result of an imbalance of asymmetric division. ${ }^{[34]}$ Understanding the mechanisms by which healthy cells lose their ability to divide asymmetrically can help determine new targets for cancer treatment and may be able to target chemoresistant and radiotherapy resistant cancer cells.

While loss of polarization and asymmetric division is thought to play a large role in cancer, the polarization of cancer cells can help advance the disease by causing metastasis. Metastasis, the complex process of establishing a new tumor at a distant site, requires that the cells first lose their epithelial polarity from cell-cell contact and regain front-to-back polarity to migrate into the circulation and extravasate at distant sites. ${ }^{[35]}$ The process of epithelial to mesenchymal transition (EMT), which is also important during development, is believed to be the mechanism by which metastasis begins. ${ }^{[35-37]}$ One of the key regulators of cell polarity, $\mathrm{Cdc} 42$, has been shown to be upregulated in cancer cells and integral in the metastatic process. ${ }^{[27,38]}$ Reymond, et al. used siRNA to show that silencing of $\mathrm{Cdc} 42$, by even just a transient depletion, prevented metastases to the lung by decreasing $\beta 1$ integrin levels and intercalation of cancer cells into the 
endothelial layers. ${ }^{[38]}$ These results showed that Cdc42 was required for transendothelial migration and that a reduction in $\operatorname{Cdc} 42$ levels was enough to reduce cancer cell migration and metastasis. Another group found similar results including a target, miR137, that can reduce Cdc42 levels and reduce colorectal cancer cell invasion. ${ }^{[39]}$ Furthermore, Kamai, et al. showed that higher expression of Cdc42 correlated with more advanced disease, furthering evidence that $\mathrm{Cdc} 42$ is crucial in cancer cell invasion and metastasis. ${ }^{[40]}$ Together, these studies show how levels of Cdc42, a known polarity regulator, play an important role in cancer progression and suggest mechanisms by which Cdc42 levels can be controlled.

\subsection{POLARIZATION AND THE IMMUNE SYSTEM}

The effects of asymmetric cell division in the immune system have been more difficult to study because of the motile nature of these cells. Studies are further complicated by the time to full differentiation, little morphological change and the relatively few cells present in the body. ${ }^{[20,41]}$ Some studies have shown a difference in fate determinant signal between daughter cells, suggesting asymmetric division occurs in hematopoietic stem cells (HSCs), however, the function of these fate determinants has not been explained in HSCs. ${ }^{[20]}$ Other proteins have been found to asymmetrically localize in HSCs resulting in one daughter cell that is more primitive than the other, confirming that intrinsic asymmetric division occurs in HSCs. ${ }^{[42]}$

While studies have shown that asymmetric division does not appear to play a large role in B cell development and differentiation, it does appear to influence T cells. ${ }^{[20,43]}$ The polarization and asymmetric division of polarity proteins and fate determinants is thought to occur after activation of the $\mathrm{T}$ cell through the T-cell receptor (TCR) and an 
antigen-presenting cell (APC). ${ }^{[4]}$ The activation of the $\mathrm{T}$ cell results in divisions that create two types of T cells: the memory T cell and the effector T cell. Memory T cells can further asymmetrically divide to give rise to the more differentiated effector $\mathrm{T}$ cell phenotype and maintain the memory $\mathrm{T}$ cell pool, indicating a stem cell-like behavior. ${ }^{[45]}$

Mechanistic studies into asymmetric division of $\mathrm{T}$ cells show that different determinants play a role during the primary and secondary response. In the primary response, CD3 and Interferon-gamma receptor (INF- $\gamma \mathrm{R})$ asymmetrically locate in memory cells but show little asymmetry in effector T cells. ${ }^{[45]}$ Further exposure to antigen can cause the central memory $\mathrm{T}$ cells to mount a secondary immune response. Here, they again divide asymmetrically to produce daughter cells that are effector T cells and central memory cells. CD25 and T-bet polarize to the effector T cell, leaving low levels of both on the other daughter cell, which remains a memory $\mathrm{T}$ cell. ${ }^{[45]}$ Interestingly, the polarization of protein kinase $\mathrm{C}$ zeta $(\mathrm{PKC}-\zeta)$ differs between the primary response and the secondary response suggesting that $\mathrm{PKC}-\zeta$ may play a role in establishing central memory. ${ }^{[45]}$

Previous studies have discovered important proteins that are polarized in T cells and regulate morphology, migration, and cell fate. ${ }^{[46]} \mathrm{T}$ cells exposed to antigen via dendritic cells polarized aPKC and Par3 proteins distal to the dendritic cell while Scribble and Discs large (Dlg) localized proximally. ${ }^{[46]}$ This proved that T cells use evolutionarily conserved mechanisms found in many organisms and cell types to asymmetrically divide. This study further showed that this polarity was important in memory $\mathrm{T}$ cell differentiation but not in effector $\mathrm{T}$ cell differentiation. ${ }^{[46]}$ Another group found that Scribble plays a major role in polarity and downregulation leading to decreased polarity 
and ability of $\mathrm{T}$ cells to migrate and present antigen. ${ }^{[47]}$ Thus, polarity in $\mathrm{T}$ cells is important for differentiation and gives the $\mathrm{T}$ cell the ability to perform the function of antigen presentation to mount an immune response.

\subsection{MICROFABRICATION TECHNIQUES TO STUDY POLARIZATION}

Microfabrication techniques have been used to understand the mechanisms responsible for asymmetric cell divisions and cell polarization and their effects on cell fate and behavior. These include the use of hydrogels, microfluidic devices and scaffolds. By utilizing these systems, many biological parameters that cannot be controlled in ordinary cell culture can now be controlled, allowing for a systematic study of individual properties of interest. These systems can be used to better mimic biological environments in vitro, providing valuable insight into cellular behavior in vivo.

One of the simplest ways to create these environments is by using microcontact printing to produce adhesive regions of varying geometries. ${ }^{[48]}$ Using this technique, groups have been able to study asymmetric division of MSCs and migration of fibroblasts and cancer cells. ${ }^{[49,50]}$ Asymmetric patterns were able to polarize the cell by asymmetric organization of the actin and microtubule cytoskeleton and resulted in biased segregation of DNA. ${ }^{[4]}$ This biased segregation was found primarily in stem cells and believed to play a role in stem cell differentiation. Work by Thery, et al. validated that anisotropy in extracellular matrix via micropatterns imposed polarity in epithelial cells by examining the organization of the actin cytoskeleton, the localization of the nucleus and the Golgi apparatus. ${ }^{[51]}$ That study not only showed the importance of ECM geometry in cell polarity but provided a tool for controlling cell polarity to determine its effects on cell behavior. 
Not only could micropatterns polarize the cell, Jiang, et al. demonstrated that cell shape asymmetry, controlled by asymmetric micropatterns, was responsible for biasing cell migration direction. ${ }^{[52]}$ In that study, cells were confined to various symmetric and asymmetric micropatterns then released from these patterns and the direction of migration recorded. This demonstrated that cell polarity biased the direction of migration even after the cell was no longer confined to the geometry. Mahmud, et al. created different symmetric and asymmetric "ratchet" micropatterns and showed that asymmetric micropatterns caused directional migration while the cells were on the patterns. ${ }^{[50]}$ Various cell types (normal and cancer cells) were used and the short-term and long-term directional biases were studied. The micropatterns polarized the Arp2/3 complex as well as the actin cytoskeleton. ${ }^{[50]}$ They concluded that the ratchet micropatterns could be used to cause directional migration of different cell types and could be used to sort cells into individual reservoirs.

Further studies into the mechanisms of biased cell migration using micropatterns showed mixed results. Kushiro found that lamellopodial extensions, controlled by Rac1, played a major role in migration directional bias. ${ }^{[53]}$ However, Kumar found that directional bias was not significantly altered by changes in Rac1, RhoA and Cdc42 expression. ${ }^{[54]}$ These discrepancies can be explained by the different cell types used and the type of expression alteration tested (Kushiro suppressed Rac1 while Kumar constitutively expressed Rac1, RhoA and Cdc42). Nevertheless, these studies begin to unravel the complexities of regulating cell migration of polarized cells.

Despite the important role of polarity in development and the immune system, few groups have employed micropatterning to study the role of polarity in cell fate 
specification. A study by Peng et al. found that induced cell anisotropy as a result of increased aspect ratio of the underlying micropattern, decreased adipogenic differentiation in MSCs and found that the optimal aspect ratio for osteogenesis was 2. ${ }^{[55]}$ While the mechanism for this phenomenon was not fully explained, it was suggested that anisotropy alters forces from the cytoskeleton and results in modified gene expression and stem cell differentiation. A study by Harris showed that MSCs on rectangles differentiated to osteoblasts in both soft and stiff matrices, while cells on squares only biased osteogenesis on the stiff matrix. While the aspect ratio of the rectangle is not reported, this study corroborates the results of Peng's study that shape and polarization caused by changes in aspect ratio play a role in stem cell fate. ${ }^{[56]}$

Micropatterning of macrophages onto elongated patterns showed that anisotropy caused M2 polarization without the presence of cytokines. ${ }^{[57]}$ Mechanistic studies found that the cytoskeleton played a critical role in the M2 polarization. These relatively few studies show the importance of cell polarity on the cytoskeleton organization and how this organization affects cell fate. However, more studies to determine the mechanisms behind polarity and cell differentiation are needed to develop better tissue engineering strategies.

Théry was also able to show that asymmetric micropatterns change the orientation of the division axis. While some asymmetric micropatterns still exhibit orientation of the division axis that would result in a symmetric division, other micropatterns bias the orientation to an asymmetric division. ${ }^{[58]}$ This bias is controlled by the torque generated by the retraction fibers and cortical cues, again demonstrating the importance of mechanics and the cytoskeleton components in polarity. Further investigation into these 
micropatterns that bias asymmetric division can provide insight into the effects on cell fate and other cellular behaviors.

Other microfabrication techniques have been employed to create polar environments including carbon nanotubes, scaffolds and microfluidic devices. By aligning carbon nanotubes, Cheng, et al. were able to control focal adhesions, cell alignment and polarity in both human umbilical vascular endothelial cells (HUVECs) and human embryonic stem cells (hESCs). ${ }^{[59]}$ Scaffolds are another way to create 3D structures to determine how cells may behave in vivo, since they provide an environment that better resembles their biological microenvironment when compared to $2 \mathrm{D}$ culture plates. Scaffolds can be made of various materials and the materials are chosen based on the biological environment mimicked and the cell type used. ${ }^{[60-62]}$ Granziano, et al. found that the material used significantly affected how dental pulp stem cells behaved and differentiated ${ }^{[63]}$ In particular, the surface geometry of the scaffold was important in polarizing the cells, proliferation rate and differentiation. Scaffolds with microconcavities that mimicked the architecture of the bone marrow had greater osteogenesis, demonstrating the importance of material geometry in scaffold design.

More recent studies by Wang, et al. successfully created scaffolds that resembled the small intestine. ${ }^{[64]}$ When cells were seeded onto these scaffolds the cells had apicalbasal polarity similar to the in vivo structure. Furthermore, cells in the crypt remained undifferentiated and migrated toward the villi. By creating these scaffolds, this group was able to recapitulate the small intestinal architecture and cell polarity, which can be used to study the small intestine in vitro or can be used to develop models of other organs. This 
technology has the potential to be used for studies such as drug delivery or cancer initiation and progression.

Scaffolds can also be used to study cell migration. Scaffolds made of polyethylene glycol (PEG) hydrogel were used to study MSC migration in real time and found that cells migrated over large distances by degrading and remodeling the scaffold. ${ }^{[65]}$ These studies can determine how and at what rate cells remodel the matrix, which are important considerations when designing scaffolds for long term use.

Microfluidic devices are also important tools to model and study cell polarity in 3D. They are easy to fabricate and have been used to study cell migration caused by chemotaxis. ${ }^{[66,67]}$ Their optical properties allow for real time measurements and visualization of cell migration that other 3D culture conditions cannot. These devices can be used to decipher the mechanisms involved in cell migration and have most often been used to characterize cancer cell migration and invasion. A recent study created a microfluidic device using selective curing that incorporated electrospun fibers. ${ }^{[68]}$ Breast cancer cells were able to migrate through the membrane toward the chemoattractant. This new platform can control various aspects of the tumor microenvironment to determine how they affect cell behavior and polarity. By using this systematic platform, methodical testing can be performed to understand how the cell-ECM interactions lead to specific cellular behaviors such as metastasis in cancer cells.

Other groups have created microfluidic devices without chemotactic gradients to monitor how cancer cells move in confined spaces. This device was used to understand how migration is affected by various chemotherapeutic drugs. ${ }^{[69]}$ They found that migration still occurred when the cells were exposed to drug concentrations above those 
required to stop proliferation, suggesting that these cells can survive treatment, migrate to distant sites and metastasize.

\subsection{FUTURE DIRECTIONS}

By creating systems that control the shape and size of the cell we can begin to understand the mechanisms of cell polarization and the effects of polarity on cell behavior. We can systematically study the role of fate determinants and polarity proteins in vitro and understand the mechanisms used by the cells. This understanding can lead to new drug targets for cancer treatment or better designed scaffolds for tissue regeneration. By understanding how our immune system reacts to antigens and how the immune cells polarize and divide we can develop better vaccines or reprogram immune systems that have begun to attack self-cells.

Further innovation is required on multiple fronts. While microfluidic devices have been used to study cancer cell migration, there have been less studies using them for polarization of immune cells or a combination of cancer cells and immune cells. Such studies would find how the two cell types interact in a biomimetic environment while still controlling other parameters. Creating these 3D systems is an improvement on 2D cell culture and is a better predictor of how these cells interact in vivo.

For stem cells, more studies using micropatterns or scaffolds can elucidate the effect of polarity on cell differentiation and determine the mechanisms by which this occurs. Furthermore, studies into cell migration and matrix remodeling will provide the necessary insight for cell retention in scaffolds and integrity of the scaffold. This is particularly important for regenerative medicine strategies that require precise mechanical properties such as bone tissue regeneration. And these studies should take 
into account recent findings that cell behavior based on substrate stiffness has been shown to be overridden by cell density. ${ }^{[70]}$ These future studies should not only determine the cellular behavior in 3D but should consider physiological parameters such as the effect of fluid flow and shear stresses that these cells will experience.

Continued studies into the impact of cell polarity on cell fate and behavior can have a large impact in multiple fields including drug development for cancer, wound healing and regenerative medicine, as well as immunology and vaccine development. In this thesis, we hope to advance this field by exploring the effects of polarity in the differentiation of hMSCs. 


\section{CHAPTER 2}

\section{THE ROLE OF CELL POLARITY AND MATRIX STIFFNESS ON STEM CELL BEHAVIOR $^{1}$}

\subsection{CELL SHAPE, POLARITY AND MATRIX STIFFNESS AND THEIR EFFECTS ON STEM CELL BEHAVIOR AND DIFFERENTIATION}

Morphological changes occur during cell differentiation, indicating a link between cell shape and function. Ingber et al. showed that disruption of the cellular native morphology using micropatterns of decreasing size prevented the cells from spreading and induced apoptosis in endothelial cells. ${ }^{[71,72]}$ Cell shape can also influence other cellular functions, such as migration, proliferation, and differentiation. ${ }^{[73,74]}$ Early studies looking at the density of the ECM and how it affects hepatocyte cell shape and spreading concluded that a low density inhibited cell spreading and growth while a high density increased spreading and proliferation and decreased differentiation. ${ }^{[75]}$ Further manipulation of the ECM by Zhang and Kilian showed that confining human mesenchymal stem cells (hMSCs) to small microislands hindered differentiation by causing lower actomyosin contractility. ${ }^{[76]}$ In addition, previous work by Kilian had demonstrated a marked effect of shape, and especially curvature, in driving differentiation of hMSCs. In that study, it was shown that shapes that induce high cell

\footnotetext{
${ }^{1}$ Piroli, M.E. and E. Jabbarzadeh. 2018. Annals of Biomedical Engineering. Reprinted here with permission from Publisher
} 
contractility promote osteogenesis while low contractility favors adipogenesis. ${ }^{[77]}$ Similar results were found in a study by McBeath et al. which concluded that the shape of cells influenced Ras homolog gene family, member A (RhoA) activity and that this was responsible for lineage commitment. ${ }^{[78]}$ These studies began to unravel the complexities of the extrinsic cues provided by the extracellular matrix, which influence cell shape and contractility, and the mechanisms by which they regulate lineage specification.

The elasticity of the ECM also plays a large role in stem cell fate. Matrices with soft stiffness similar to bone marrow, cause cells to have small, rounded morphology and be quiescent. ${ }^{[79]}$ In a pioneering study, the link between physiological stiffness and lineage commitment was established by Engler et al., who subjected MSCs and myoblasts to gels of different stiffness and found that cell fate specification was based on how well the gel's stiffness matched that of the physiological tissue. ${ }^{[80,81]}$ Very soft matrices of up to $1 \mathrm{kPa}$ that mimic the brain microenvironment result in MSC differentiation to neurons. Meanwhile, slightly stiffer matrices of 8-17 $\mathrm{kPa}$ cause myogenesis, and stiff matrices of $25-40 \mathrm{kPa}$ lead to osteogenesis. ${ }^{[80]}$ Matrix stiffness can also directly influence cell shape by allowing the cell to go from a round morphology to a spread and branched shape as stiffness increases. ${ }^{[82-84]}$ The interplay between matrix elasticity and shape provide biophysical cues that drive cell division, cell fate, and differentiation.

While matrix elasticity and shape are extrinsic cues for asymmetric division, polarization is an intrinsic control. Polarization is a key factor in normal development, cell differentiation, and tumor suppression. ${ }^{[85,86]}$ A lack of polarization promotes pluripotency in embryonic stem cells, disrupting normal development. ${ }^{[87]}$ Studies in 
organisms such as C. elegans and Drosophila have been able to pinpoint the molecules involved in polarization and subsequent asymmetric divisions, and these molecules appear to be conserved in mammals as well. ${ }^{[7]}$ There are various types of polarities (planar, epithelial, apical-basal, immunological, etc.) and each is regulated by different proteins. For example, differentiation and stratification of mammalian skin is caused by the apical localization of aPKC, Par3-LGN-Inscutable complex, and NuMA-dynactin. ${ }^{[88]}$ While in the mammalian hematopoietic system, Notch signaling is responsible for polarity. ${ }^{[7]}$ These polarity cues determine the cytoskeleton organization and the axis of division. ${ }^{[89]}$ In a seminal study, Théry et al. was able to demonstrate that by changing the ECM geometry, polarity was induced in the cell influencing the cell division axis orientation and the organization of organelles within the cell. ${ }^{[00]} \mathrm{A}$ different study showed that ECM also helps to establish polarity by signaling through cellular integrin and receptor contacts. ${ }^{[91]}$ These findings suggest that extrinsic cues from the microenvironment can control intrinsic factors associated with cell division and fate.

Asymmetric division is not solely controlled by any of the above, but rather the interplay between all aspects determines the type of cell division or lineage commitment. To deconstruct the interplay between matrix elasticity and geometry, our lab previously used ultraviolet (UV) lithography to create three shapes (circle, square and rectangle) in three different sizes $\left(1000,2500\right.$, and $\left.5000 \mu \mathrm{m}^{2}\right)$ featuring three different elasticities $(7$, 47 and $105 \mathrm{kPa}$ ). We found that at the smallest size, elasticity and shape did not play a role in lineage commitment and cells underwent adipogenesis. On the larger sizes, an interplay between shape and elasticity was identified, with shape cues capable of overriding cues from the matrix elasticity. ${ }^{[92]}$ Lee et al. also showed a connection between 
shape and matrix stiffness in osteogenesis, demonstrating that shape could enhance the amount of osteogenesis observed as the matrix stiffness increased. ${ }^{[93]}$ Previous work has also shown MSCs can modulate their lineage commitment when there is a shift in their matrix stiffness. The study found that switching stem cells from soft to stiff matrix changed the expression of lineage markers from neurogenic to osteogenic. Furthermore, a shift from an unpatterned matrix to a patterned matrix enhanced the change in lineage marker expression depending on the shape, indicating that cell geometry provides important cues for lineage specification. ${ }^{[82]}$ While multiple studies have found a connection between matrix stiffness and cell shape, there have been a lack of studies on the interplay between polarization and matrix stiffness and their effect on cell differentiation.

\subsection{AIMS OF THESIS}

In this thesis, we aim to elucidate the dynamics between polarity, matrix stiffness, and lineage commitment of hMSCs. From previous studies by our and other groups we know that soft matrix stiffness will induce adipogenesis, while stiffer matrices induce osteogenesis, Figure 2.1. Furthermore, symmetric and circular shapes bias adipogenesis.

In this work, micropatterning techniques are used to create polyethylene glycol (PEG) hydrogels of soft $(\sim 5 \mathrm{kPa})$ and hard $(\sim 230 \mathrm{kPa})$ stiffness and patterns featuring different shapes $(\mathrm{O}, \mathrm{Y}$ and $\mathrm{T})$ to induce cell polarity. By exposing hMSCs to the different combinations of matrix stiffness and ECM shape, we test two central hypotheses: (1) extrinsic cues from the ECM geometry can induce internal cell polarity and (2) the sensitivity of cells to geometric polarity signals is dependent on the stiffness of ECM. The hydrogel stiffness chosen span ranges known to induce adipogenesis and 
Soft: 1-7 kPa

Adipogenesis

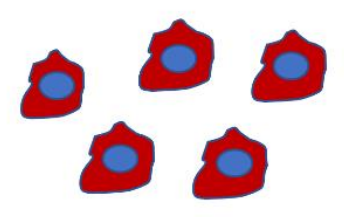

$\tilde{\omega}$
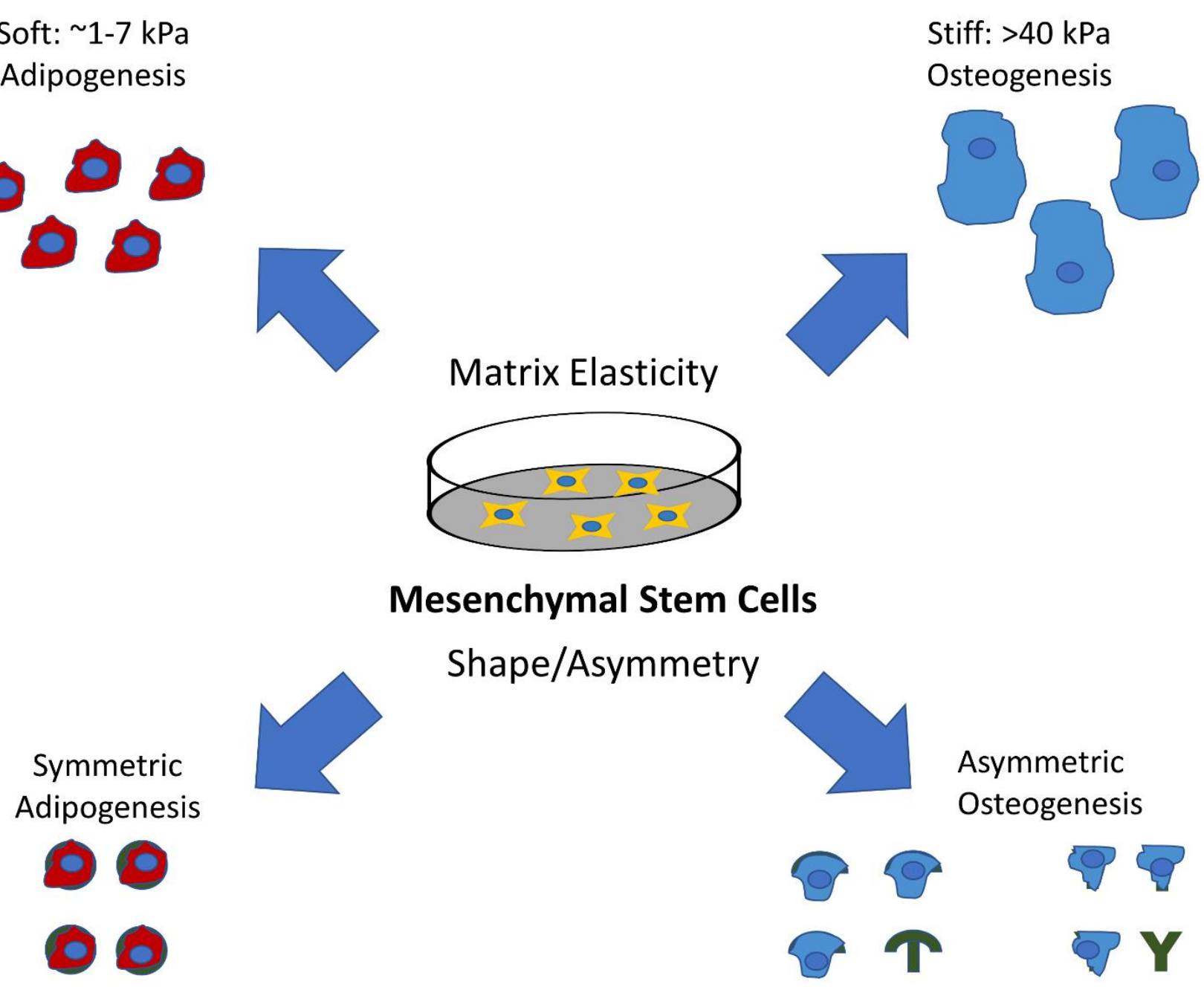

Figure 2.1: Schematic of the effects of matrix elasticity and cell asymmetry on mesenchymal stem cell lineage. 
osteogenesis and the shapes range from nonpolar circles with multiaxial symmetry to more polarizing shapes such as $\mathrm{T}$ and $\mathrm{Y}$ with only one axis of symmetry, subsequently referred to as "asymmetric". Our work shows that cell polarity induced by ECM geometry provides osteogenic inductive signals at low matrix stiffness. 


\section{CHAPTER 3 \\ MATERIALS AND METHODS}

\subsection{PURPOSE}

To achieve our goal of testing the interplay between cues from the mechanical properties of the extracellular matrix and cell polarity we created cell culture environments that would allow specific control of the ECM stiffness and cell shape. We created these environments using the schematic in Figure 3.1. Incubating cells in these environments along with soluble differentiation cues in the cell culture media allowed us to quantify how the cells responded to both the mechanical and polarity cues.

\subsection{SURFACE PREPARATION}

Glass slides $(22 \times 22 \mathrm{~mm}, \mathrm{VWR})$ were cleaned using a sonicator with $70 \%$ ethanol for 10 minutes and dried with nitrogen gas. The slides were then sputter coated with a $5 \mathrm{~nm}$ layer of titanium (Denton Desk II TSC, Moorestown, NJ) followed by a 40 nm layer of gold (Denton Desk II, Moorestown, NJ). The coated slides were stored at room temperature until further use.

\subsection{MICROPATTERN FABRICATION}

Micropatterns were designed using Autocad software (Autodesk, San Rafael, CA) and printed on transparencies $(\mathrm{CAD} / \mathrm{Art}$ Services, Inc. Bandon, $\mathrm{OR})$ to create photomasks. A hydrogel precursor, consisting of 700 MW PEG-DA (Sigma-Aldrich, St. Louis, MO), 2,000 MW 4-arm PEG-SH (CreativePEGWorks, Chapel Hill, NC), 1\% 2hydroxy-2-methylpropriophenone (Sigma-Aldrich, St. Louis, MO), and water, was placed 

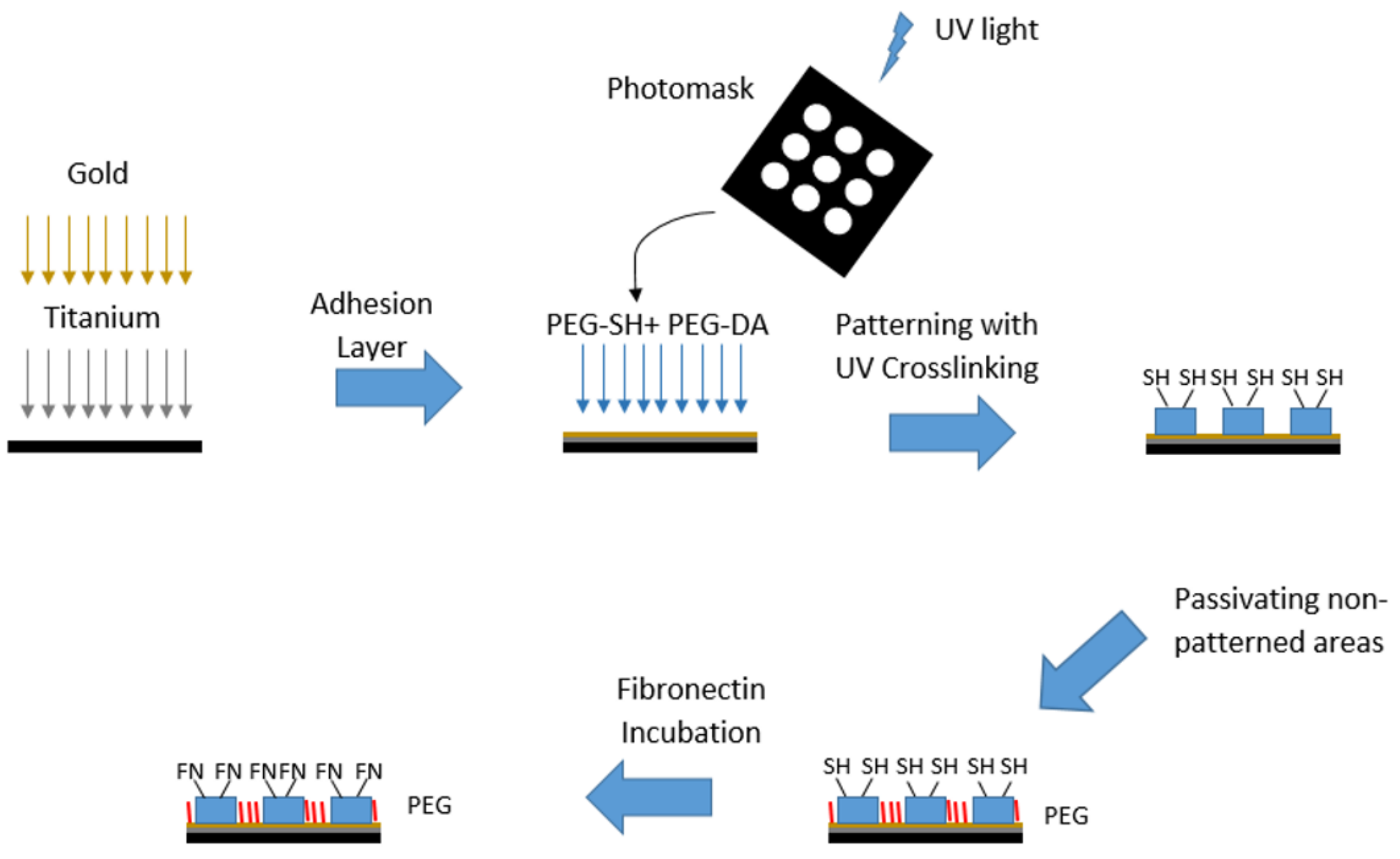

Figure 3.1: Schematic of micropatterned hydrogel process. 
on the gold slides followed by the photomask and allowed to polymerize under UV light (UVP, Upland, CA). The unpatterned regions were passivated with triethylene glycol mono-11-mercaptoundecyl ether (Sigma-Aldrich, St. Louis, MO) to prevent protein binding. The slides were then rinsed with 70\% ethanol followed by phosphate-buffered saline (PBS) before protein incubation. Fibronectin was allowed to conjugate with heterogeneous maleimide/N-hydroxysuccinimide crosslinker (Thermo Fisher, Waltham, MA) for one hour at room temperature before using a ZebaSpin desalting column (Thermo Fisher, Waltham, MA) to separate the functionalized protein from unreacted crosslinker. Conjugated fibronectin was then incubated on the patterned slides for 4 hours at room temperature and then overnight at $4{ }^{\circ} \mathrm{C}$.

\subsection{HYDROGEL MECHANICAL CHARACTERIZATION}

Hydrogel discs of approximately $6.5 \mathrm{~mm}$ in diameter and $2 \mathrm{~mm}$ in height were created using the same formulation as mentioned previously. The discs were incubated in PBS at $37{ }^{\circ} \mathrm{C}$ for 48 hours prior to testing under unconfined compression at $0.05 \mathrm{~mm} / \mathrm{s}$ using an Electroforce 3200 (Bose, New Castle, DE). The Young's modulus was then calculated based on the force applied and displacement measured.

\subsection{CELL CULTURE}

Human bone-marrow derived mesenchymal stem cells were purchased from Lonza (Walkersville, MD). The hMSCs were grown in mesenchymal stem cell basal medium (Lonza, Walkersville, MD) supplemented with MSCGM $^{\mathrm{TM}}$ SingleQuots ${ }^{\mathrm{TM}}$ (mesenchymal cell growth supplement, L-glutamine, and GA-1000) in T-75 culture flasks. The cells were allowed to reach $80 \%$ confluence before passaging with $0.25 \%$ trypsin-EDTA (Corning, Manassas, VA). Cells up to passage 6 were used and seeded on 
substrates at 5000 cells $/ \mathrm{cm}^{2}$. Cells were given up to a day to attach before switching to differentiation media consisting of 1:1 adipogenic to osteogenic medium. Adipogenic medium was made using Dulbecco's Modified Eagle Medium (DMEM) (Invitrogen, Carlsbad, CA), 10\% fetal bovine serum (FBS) (FB Essence, VWR, Radnor, PA), $1 \mu \mathrm{M}$ dexamethasone (Sigma-Aldrich, St. Louis, MO), $10 \mu \mathrm{M}$ insulin (Sigma-Aldrich, St. Louis, MO), $200 \mu \mathrm{M}$ indomethacin (Sigma-Aldrich, St. Louis, MO), $0.5 \mathrm{mM}$ isobutylmethylxanthine (Sigma-Aldrich, St. Louis, MO), and $1 \%$ penicillin/streptomycin (Hyclone, Chicago, IL). The osteogenic medium contained DMEM/F-12 (Hyclone, Chicago, IL), 10\% FBS (FB Essence, VWR, Radnor, PA), $10 \mathrm{mM} \beta$-glycerophosphate (Sigma-Aldrich, St. Louis, MO), $50 \mu \mathrm{g} / \mathrm{mL}$ ascorbic acid (Sigma-Aldrich, St. Louis, MO), $1 \mu \mathrm{M}$ dexamethasone, and 1\% penicillin/streptomycin (Hyclone, Chicago, IL). Inhibition media was made by adding $1 \mu \mathrm{M}$ nocodazole (Sigma-Aldrich, St. Louis, MO) or $2 \mu \mathrm{M}$ Y-27632 (Calbiochem CAS, San Diego, CA) to the differentiation media and changed daily.

\subsection{IMMUNOCYTOCHEMISTRY AND HISTOLOGICAL STAINING}

Cells were fixed with $4 \%$ paraformaldehyde (Sigma-Aldrich, St. Louis, MO), permeabilized with $0.1 \%$ Triton X-100 in PBS, and blocked using $1 \%$ BSA. The actin cytoskeleton, nucleus, and LGN were stained with phalloidin-rhodamine (Sigma-Aldrich, St. Louis, MO), DAPI (Sigma-Aldrich, St. Louis, MO), and anti-GPSM2 (Sigma-Aldrich, St. Louis, MO), respectively. Fluorescent images were captured using a Nikon eclipse 80i microscope with CoolSnap HQ camera. Fate specification was determined with dual staining of alkaline phosphatase and Oil Red O for osteogenesis and adipogenesis, respectively, and imaged using a Nikon E600 microscope with a color camera. Cells with 
lipid vacuoles stained red and were considered adipocytes. Cells that stained deep purple were determined to be osteoblasts.

\subsection{STATISTICAL ANALYSIS}

Values graphed represent mean \pm SEM. Statistical analysis was performed using Microsoft Excel. One factor ANOVA and two-tailed student t-test were used to calculate p-values. Data were from at least two independent experiments with at least 50 cells for each condition. Significance was set at $\mathrm{p}<0.05$. 


\section{CHAPTER 4}

\section{RESULTS}

\subsection{CELL DENSITY AND MATRIX ELASTICITY BOTH INFLUENCE hMSC DIFFERENTIATION}

Researchers have shown that MSC cell fate is influenced by seeding density and the stiffness of the environment. ${ }^{[92,}{ }^{94]}$ We seeded hMSCs onto glass coverslips and exposed them to lineage specific medium and observed a difference in the percent of cells that differentiated to adipocytes and osteoblasts based on whether the cells were seeded at low $\left(5,000\right.$ cells $\left./ \mathrm{cm}^{2}\right)$ or high densities $\left(25,000 \mathrm{cells} / \mathrm{cm}^{2}\right)$ (Figure 4.1$)$. In strictly adipogenic medium, an increase in seeding density increased adipogenesis from $72.6 \pm 7.4 \%$ at low density to $92.1 \pm 0.9 \%$ at high density. Changes in seeding density had less of an effect on osteogenesis in osteogenic medium, with $99.4 \pm 1.0 \%$ of differentiated cells identified as osteoblasts in low seeding density conditions and $98.4 \pm 0.8 \%$ at high seeding density. When exposed to a 1:1 ratio of adipogenic to osteogenic medium, a change in seeding density caused a decrease in osteogenesis, from $98.2 \pm 0.9 \%$ at low density to $54.9 \pm 2.2 \%$ at high density (Figure 4.1 ). These results show high density seeding favors adipogenic differentiation, consistent with previous findings. ${ }^{[94]}$

To determine the effects of matrix elasticity on hMSC differentiation, 20\% PEG hydrogels $(230 \mathrm{kPa})$ were made and the cells were exposed to the mixed adipogenic/osteogenic medium. This resulted in $69.9 \pm 3.4 \%$ of the cells differentiating to osteoblasts at low seeding density and $45.2 \pm 3.4 \%$ at high seeding density, demonstrating 


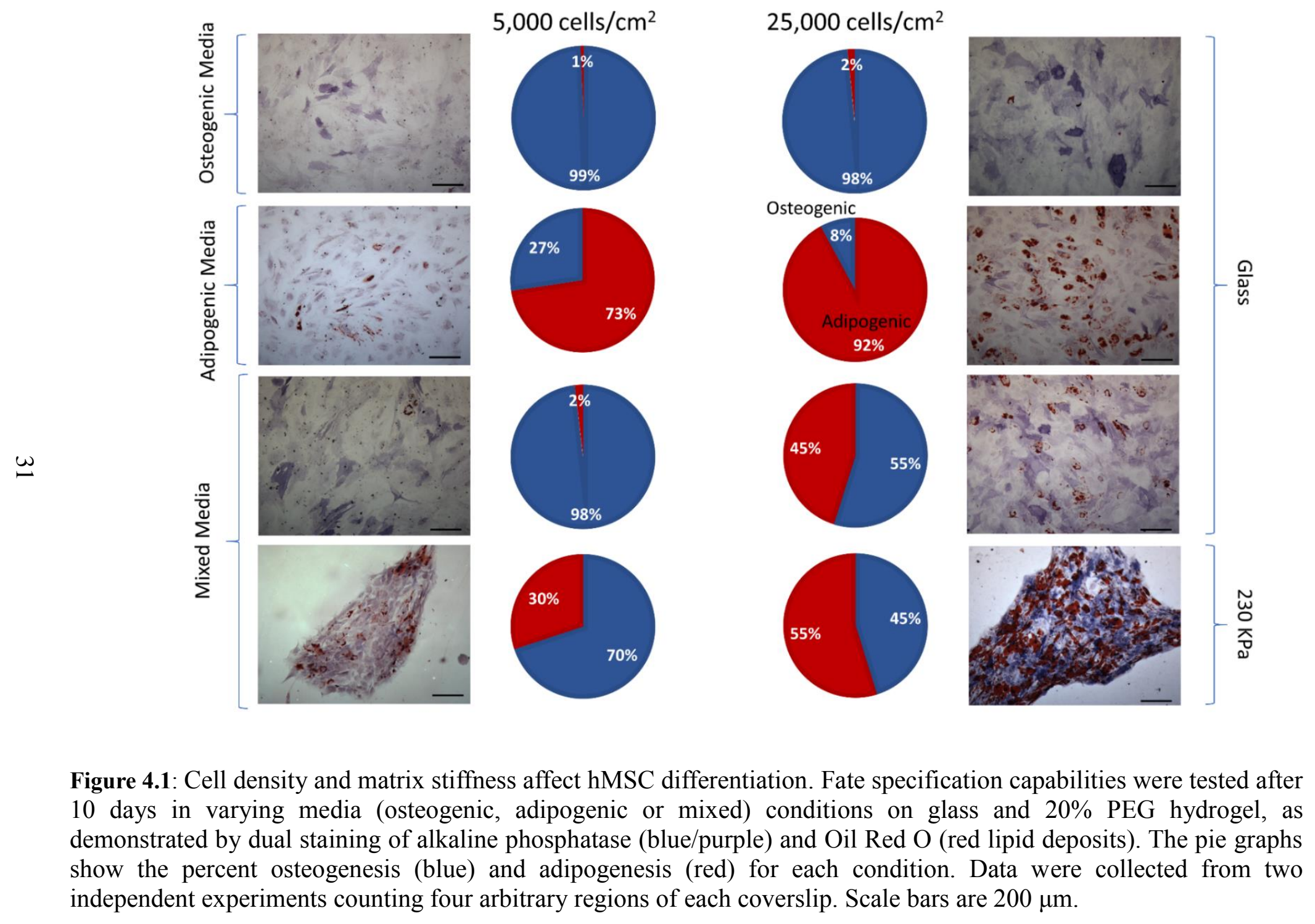

25,000 cells $/ \mathrm{cm}^{2}$

Figure 4.1: Cell density and matrix stiffness affect hMSC differentiation. Fate specification capabilities were tested after 10 days in varying media (osteogenic, adipogenic or mixed) conditions on glass and 20\% PEG hydrogel, as demonstrated by dual staining of alkaline phosphatase (blue/purple) and Oil Red O (red lipid deposits). The pie graphs independent experiments counting four arbitrary regions of each coverslip. Scale bars are $200 \mu \mathrm{m}$. 
that softer substrates favor adipogenesis (Figure 4.1). These results confirm that matrix stiffness and seeding density, which affect cell-cell contact, cell shape, and cell size, are all both important cues in hMSC differentiation.

\subsection{MICROPATTERNS INDUCE POLARIZATION OF LGN PROTEIN AND CYTOSKELETON IN hMSCs}

To control individual hMSC cell polarity and shape while preventing cell-cell contact, we used UV lithography to micropattern three different configurations $(\mathrm{O}, \mathrm{T}$, and Y) on a hydrogel surface (Figure 4.2B). The patterning process, Figure 3.1, begins by creating a gold adhesion layer on a glass slide, followed by deposition of the hydrogel precursor, which was composed of polyethylene glycol diacrylate (PEG-DA) and PEGSH. Subsequent UV exposure through a photomask enabled crosslinking of the polymer in the desired regions. The non-patterned areas were then passivated to prevent protein or cells from binding. Functionalized fibronectin was then incubated with the polymer, selectively binding to the exposed thiol groups, to render the patterned regions cell adhesive (Figure 3.1). To ensure preferential binding of the protein to the patterned regions, fluorescein isothiocyanate (FITC) conjugated bovine serum albumin was functionalized and incubated on the patterned hydrogels. As shown in Figure 4.2B, only the patterned regions were fluorescent, indicating a non-adhesive background. Stem cells were seeded onto the patterned substrate and allowed to adhere. Individual cells spread and assumed the shape of the underlying pattern (Figure 4.2C).

To confirm polarization, the nucleus was localized by staining with 4',6Diamidino-2-Phenylindole (DAPI), the organization of the cytoskeleton was examined by staining for F-actin and the localization of the polarity protein G protein signaling modulator 2 (GPSM2), was determined by staining with anti-LGN antibody (Figure 4.3). 
Symmetric 0

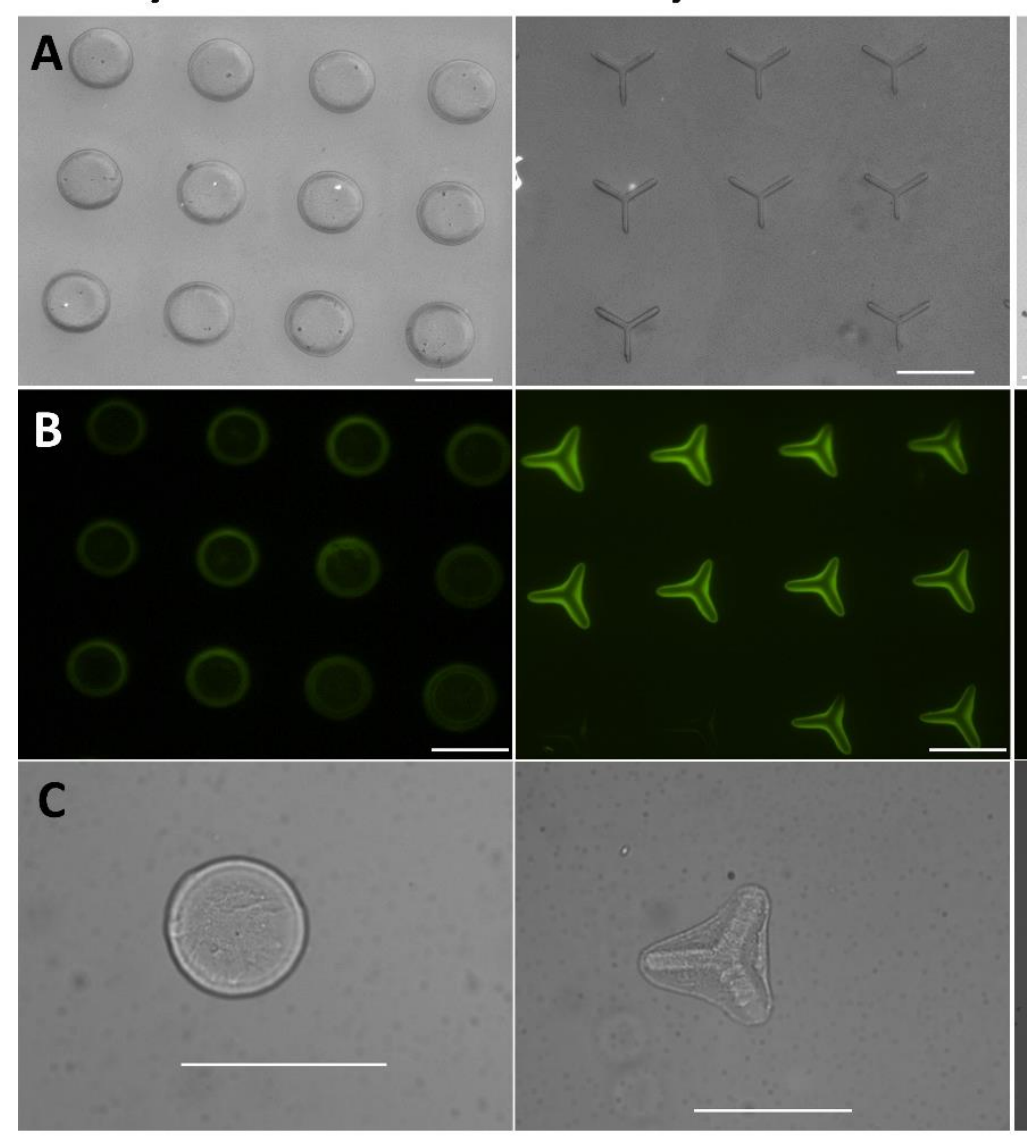

Asymmetric T
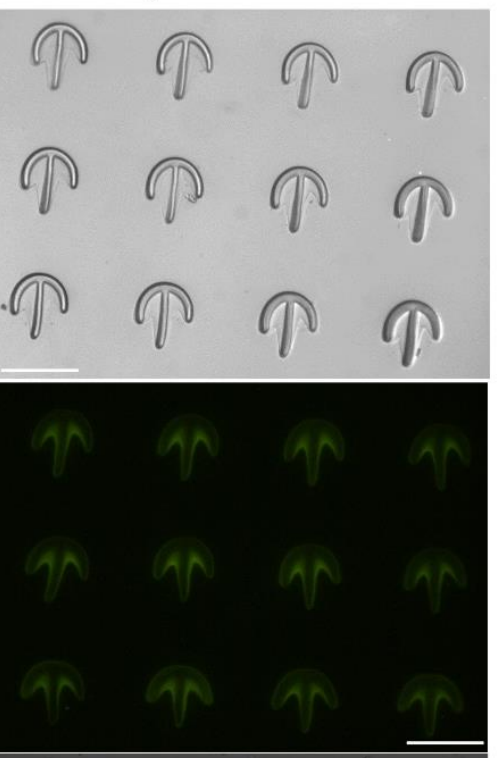

Figure 4.2: Micropatterned hydrogels. A) Crosslinking only occurred through the transparent micropattern region. B) Fluorescent Bovine Serum Albumin was used to confirm that protein binding was only on the micropatterned regions. C) Cells were able to attach to the micropatterns and spread over the entire shape. 


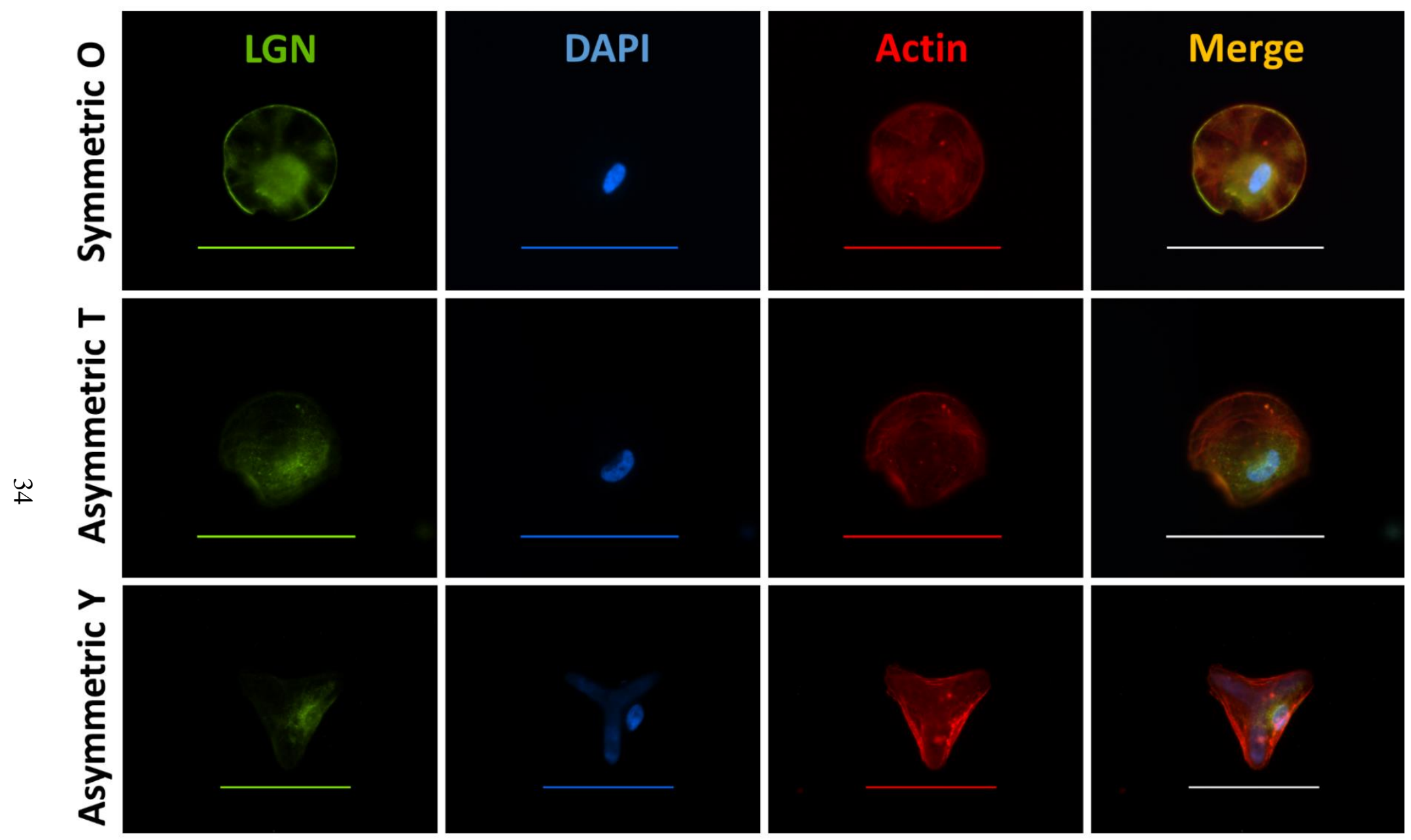

Figure 4.3: hMSCs adopt the shape of the underlying hydrogel patterns. Asymmetric configurations result in internal polarization. LGN polarity protein (green) is localized near the nucleus, and the actin cytoskeleton aligns along the non-adhesive regions. Scale bars are $100 \mu \mathrm{m}$ 
LGN localization was of interest because it has been shown to be important in establishing cellular polarity and lack of polarization resulting in disease. ${ }^{[88,}$ 95, 96] Furthermore, LGN levels and localization dictate cell migration, focal adhesions and differentiation. ${ }^{[97-99]}$ On the symmetric patterns $(\mathrm{O})$, the stained images showed the actin cytoskeleton was evenly distributed throughout and the nucleus was close to the center of the cell. Additionally, the polarity protein, LGN, was evenly distributed around the nucleus, indicating the hMSCs were non-polarized. In contrast, we observed polarization of the hMSCs that had spread on the $\mathrm{T}$ and $\mathrm{Y}$ shapes. On the asymmetric $\mathrm{T}$ shape, the nucleus was no longer localized in the center of the cell, but instead was positioned distal to the adhesive regions. The actin cytoskeleton was aligned along the non-adhesive sides in agreement with a previous study by Théry. ${ }^{[90]}$ The LGN protein localized near the nucleus, resulting in an asymmetric distribution towards the non-adhesive region. Similarly, the actin cytoskeleton of the cells on Y shaped patterns aligned along the nonadhesive regions, with the nucleus polarized to one side and the LGN protein concentrated around the nucleus. Thus, we confirm polarization of the cells by polarization of the cytoskeleton and internal polarization of the organelles and polarity proteins.

\subsection{POLARIZATION AND MATRIX STIFFNESS BOTH CONTRIBUTE TO hMSC LINEAGE COMMITMENT}

To understand the combined roles of matrix elasticity and cell polarization on hMSC lineage commitment, we cultured asymmetric and symmetric patterned cells on hydrogels featuring soft $(\sim 5 \mathrm{kPa})$ and hard $(\sim 230 \mathrm{kPa})$ stiffness for 10 days in mixed adipogenic/osteogenic differentiation media. Cells were fixed and stained for alkaline phosphatase and lipid deposits using Oil Red O and counted. Cells that stained positive 
for alkaline phosphatase were purple and counted as osteoblasts, while cells with lipid deposits were stained red and counted as adipocytes (Figure4.4E). On the soft matrix, the symmetric cell shape (O) resulted in a mixed population of adipocytes $(52.1 \%)$ and osteoblasts (47.9\%) (Figure 4.4A). In contrast, confinement to asymmetric hydrogel microislands shifted fate specification toward osteogenesis. Cells on the asymmetric $\mathrm{T}$ shape microislands had a decrease of adipogenesis to $27.4 \%$ and an increase of osteogenesis to $72.6 \%$. Cells on the $\mathrm{Y}$ shape had an even greater bias toward osteogenesis, with $86.0 \%$ of cells identified as osteoblasts and only $14.0 \%$ as adipocytes. The significant increase in osteogenesis on asymmetric patterns in the soft matrix shows that cell polarity signals tune cell fate specification and differentiation under these conditions.

However, on the stiff matrix, we observed no significant difference in terms of lineage specification between cells cultured on symmetric and asymmetric ECM islands (Figure 4.4B). Osteogenesis for all shapes was similar, with cells on the symmetric shape having the least osteogenesis at $74.1 \%$. MSCs on asymmetric patterns resulted in a slight increase of osteogenesis to $74.2 \%$ in cells cultured on $\mathrm{T}$ and $79.4 \%$ of cells on the $\mathrm{Y}$ shape patterns. Clearly, at sufficiently high matrix stiffness, cells are biased toward osteogenesis and are not influenced by geometric asymmetry signals.

\subsection{CYTOSKELETAL INHIBITORS DAMPEN ASYMMETRIC SIGNALING}

To confirm the role of matrix mechanics in cell fate decisions, we used pharmaceuticals Y-27632 and nocodazole to disrupt the cytoskeleton and make the cell insensitive to the matrix stiffness. Y-27632 is a ROCK inhibitor that has been shown to diminish stress fibers in cells and decrease cytoskeletal tension. ${ }^{[100,101]}$ On the other hand, 

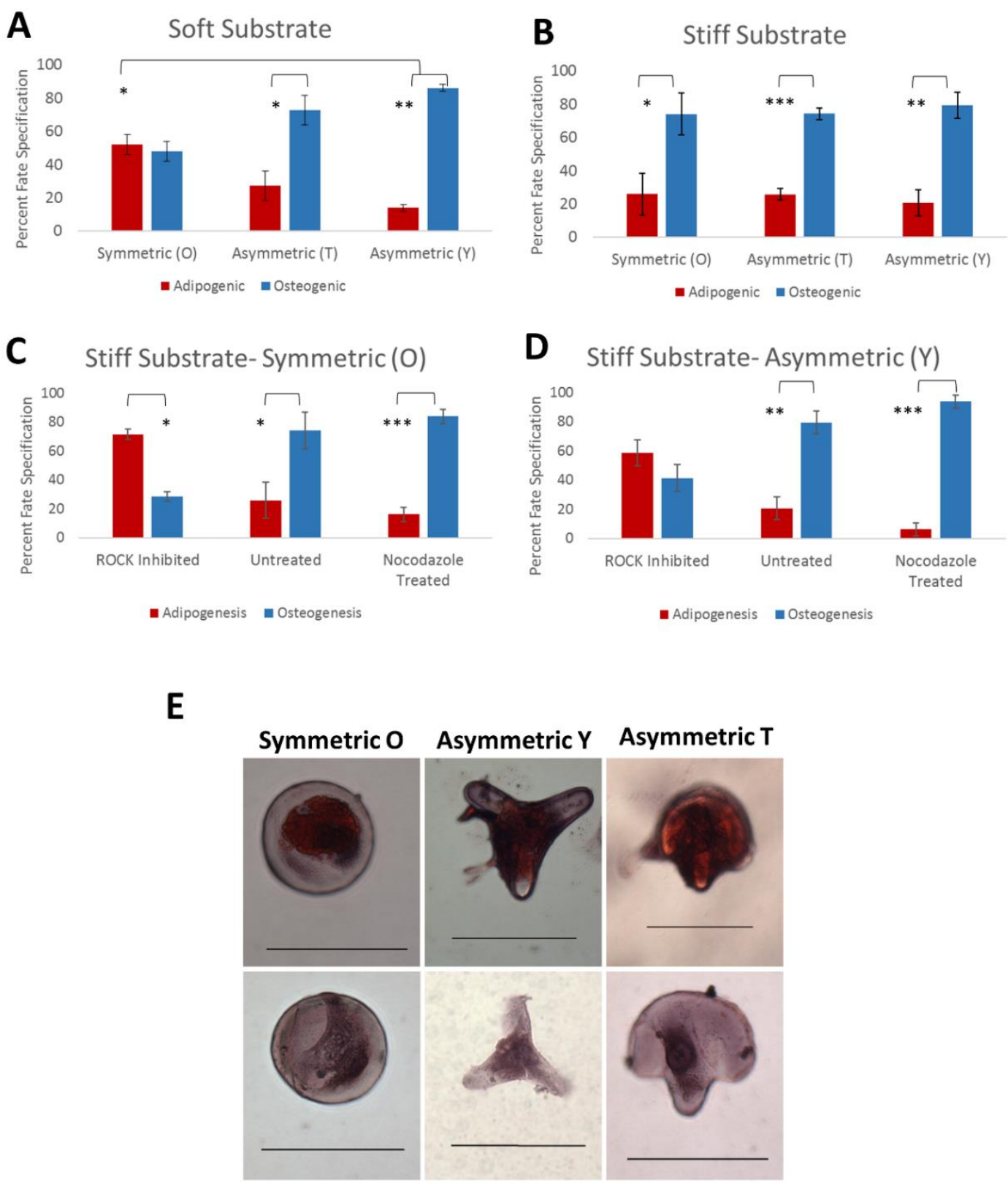

Figure 4.4: Asymmetry and matrix elasticity both play a role in hMSC lineage commitment. (A) Asymmetry has a significant role in osteogenesis in the soft matrix $(\mathrm{n}=4)$ (B) High matrix stiffness overrides asymmetry signals resulting in similar osteogenesis in all three shapes $(n=4)(C-D)$ ROCK inhibitor, Y-27632, can override matrix stiffness, favors adipogenesis in the $\mathrm{O}$ and disrupts the osteogenic bias of the $\mathrm{Y}$ shape. Nocodazole treatment enhances osteogenesis in both shapes. (E) Representative images of adipocytes and osteoblasts on $\mathrm{O}, \mathrm{T}$, and $\mathrm{Y}$ shapes. Bars represent mean \pm standard error with more than 50 cells per condition. Statistical significance was evaluated using one-way ANOVA, $*=\mathrm{p}<0.05, * *=\mathrm{p}<0.01, * * *=\mathrm{p}<0.001$. Scale bars are $100 \mu \mathrm{m}$. 
nocodazole stabilizes microtubules and increases the cell contractility by activating RhoA and ROCK. ${ }^{[102,103]}$ We seeded the hMSCs onto the representative symmetric $(\mathrm{O})$ and asymmetric (Y) PEG hydrogels and allowed them to adhere and spread in growth medium before switching to mixed adipogenic/osteogenic differentiation medium containing either inhibitor. After 10 days, the percent of osteogenic cells on the symmetric patterns treated with Y-27632 decreased from $74.1 \%$ to $28.6 \%$ (Figure 4.4C). In contrast, after 10 days of nocodazole treatment osteogenesis increased from $74.1 \%$ to 83.8\%. Similarly, Y-27632 decreased the percent of osteogenesis in the asymmetric Y shape from $79.4 \%$ to $41.4 \%$ and nocodazole treatment increased osteogenesis from $79.4 \%$ to $93.8 \%$ (Figure 4.4D). These results demonstrate that ROCK inhibition switches the differentiation trend from osteogenesis to adipogenesis, while nocodazole treatment enhances osteogenesis. The difference in osteogenesis and adipogenesis in the ROCK inhibited group was significant in the symmetric shape but not significant for the asymmetric shapes, implying that asymmetry in the cell can still partially drive osteogenesis when matrix stiffness is no longer a factor. 


\section{CHAPTER 5}

\section{CONCLUSIONS}

In this study, we used micropatterning to determine the combinational roles of cell polarity and matrix stiffness on hMSC differentiation. By creating symmetric and asymmetric shapes on patterned hydrogels with tunable mechanical properties, we were able to isolate each effect at the individual cell level. Our patterned hydrogel microislands were able to control environmental cues, such as cell size, cell-cell contact, and ligand density, which have all been shown to influence stem cell behavior. ${ }^{[78,104,105]}$ hMSCs were able to survive on the hydrogel patterns for 10 days and differentiate into adipogenic or osteogenic lineages. The cells were able to integrate signals resulting from polarization due to ECM geometry and matrix stiffness to determine lineage specification.

While the role of biophysical cues in differentiation have been well studied, the effect of polarization is still poorly understood. Studies have shown that a lack of polarization can lead to improper development of the cochlea (resulting in deafness), polycystic kidney disease, and cancer. ${ }^{[106,107]} \mathrm{A}$ better understanding of how to induce polarity in cells could help to prevent such diseases. Théry et al. showed that micropatterns were capable of polarizing the internal organization of the cell including the nucleus, Golgi apparatus, centrosome, and microtubules, concluding that matrix geometry had the ability to induce internal cell polarity in endothelial cells. ${ }^{[90]}$ Our study showed that polarization of stem cells could be achieved using similar micropatterns. The 
patterns not only polarized the actin cytoskeleton, but also affected the internal organization of the organelles and polarity protein distribution (Figure 4.3). This proved that matrix geometry provides the cell with cues that can change its internal organization, including mitotic spindle orientation, and can drive asymmetric divisions and fate specification. ${ }^{[108,109]}$ This platform could be used to study effects of polarization at the single cell level in other biological phenomenon such as epithelial-mesenchymal transition.

Our results demonstrate an interplay between polarity and matrix elasticity in regulation of cell processes. On a soft matrix $(\sim 5 \mathrm{kPa})$, polarity had the greatest impact on fate specification. According to our results, symmetry does not bias specification to adipocytes or osteoblasts, while induction of polarity with asymmetric micropatterns favored osteogenesis (Figure 4.4A). This bias toward osteogenesis suggests polarity activates signaling pathways that either inhibit adipogenesis or promote osteogenesis. Our findings suggest that at low matrix stiffness, the cell receives signals from polarity cues that drive cells toward an osteogenic fate.

Polarity signaling, however, has its limitations. At the higher matrix stiffness $(\sim 230 \mathrm{kPa})$, we observed the role of polarity signaling disappear. All shapes, polar and non-polar, were biased toward osteogenesis and resulted in similar proportions of osteogenic cells. This shows that matrix stiffness can override polarity signaling. High matrix stiffness has been shown to activate ROCK/RhoA signaling, which is responsible for osteogenesis and mechanotransduction. ${ }^{[110-112]}$ Thus, matrix stiffness and polarity could work through the same ROCK/RhoA signaling pathway, with high matrix stiffness 
playing a larger role in activating it and thus resulting in regions where polarity does not provide the cell with differentiation cues.

This study used the Young's modulus to characterize the mechanics of the hydrogel. While this measurement does not provide full details of the mechanical properties of the hydrogel or give insight into ECM and cell dynamic interactions, its purpose was to create two different environments that could bias osteogenic and adipogenic differentiation. Further characterization of the hydrogels after cell differentiation could help to understand how the cells interact with their matrix. To develop better stem cell therapies or regenerative medicine strategies, it would be important to understand how these cells behave in situ and create hydrogels that mimic these matrix properties. Nevertheless, the difference in cell behavior based on matrix stiffness was evident and shows that a better understanding of ECM mechanics is required to further explain cell differentiation.

Biophysical cues have been known to play a major role in stem cell differentiation. Here we show that the interplay between cell polarity and matrix stiffness can drive osteogenesis in hMSCs. By beginning to unravel this relationship, we can start to understand the intricacies of development and regenerative medicine. We can further test the behavior of other cells of interest (e.g., embryonic stem cells) to see how perturbations in polarity or matrix stiffness can cause developmental defects or disease. 


\section{REFERENCES}

[1] Nelson, W.J. Adaptation of core mechanisms to generate cell polarity. Nature. 422: 766-74, 2003.

[2] Gong, Y., C. Mo, and S.E. Fraser. Planar cell polarity signalling controls cell division orientation during zebrafish gastrulation. Nature. 430: 689, 2004.

[3] Vicente-Manzanares, M., D.J. Webb, and A.R. Horwitz. Cell migration at a glance. Journal of Cell Science. 118: 4917-4919, 2005.

[4] Drubin, D.G. and W.J. Nelson. Origins of Cell Polarity. Cell. 84: 335-344, 1996.

[5] Etienne-Manneville, S. and A. Hall. Cell polarity: Par6, aPKC and cytoskeletal crosstalk. Current Opinion in Cell Biology. 15: 67-72, 2003.

[6] Mlodzik, M. Planar cell polarization: do the same mechanisms regulate Drosophila tissue polarity and vertebrate gastrulation? Trends Genet. 18: 564-71, 2002.

[7] Knoblich, J.A. Mechanisms of Asymmetric Stem Cell Division. Cell. 132: 583$597,2008$.

[8] Lechler, T. and E. Fuchs. Asymmetric cell divisions promote stratification and differentiation of mammalian skin. Nature. 437: 275-280, 2005.

[9] Powell, D.W. Barrier function of epithelia. American Journal of PhysiologyGastrointestinal and Liver Physiology. 241: G275-G288, 1981.

[10] Pilot, F. and T. Lecuit. Compartmentalized morphogenesis in epithelia: from cell to tissue shape. Dev Dyn. 232: 685-94, 2005.

[11] Nelson, W.J. Remodeling epithelial cell organization: transitions between frontrear and apical-basal polarity. Cold Spring Harb Perspect Biol. 1: a000513, 2009.

[12] Takano, T., C. Xu, Y. Funahashi, T. Namba, and K. Kaibuchi. Neuronal polarization. Development. 142: 2088-2093, 2015.

[13] Witte, H. and F. Bradke. The role of the cytoskeleton during neuronal polarization. Curr Opin Neurobiol. 18: 479-87, 2008.

[14] Conklin, E.G., The Organization and Cell-lineage of the Ascidian Egg. 1905, Philadephia, PA.

[15] Knoblich, J.A. Asymmetric cell division: recent developments and their implications for tumour biology. Nat Rev Mol Cell Biol. 11: 849-60, 2010.

[16] Knoblich, J.A. Mechanisms of asymmetric stem cell division. Cell. 132: 583-97, 2008.

[17] Schneider, S.Q. and B. Bowerman. Cell polarity and the cytoskeleton in the Caenorhabditis elegans zygote. Annu Rev Genet. 37: 221-49, 2003.

[18] Neumüller, R.A. and J.A. Knoblich. Dividing cellular asymmetry: asymmetric cell division and its implications for stem cells and cancer. Genes \& Development. 23: 2675-2699, 2009. 
[19] Guo, S. and K.J. Kemphues. par-1, a gene required for establishing polarity in C. elegans embryos, encodes a putative Ser/Thr kinase that is asymmetrically distributed. Cell. 81: 611-620, 1995.

[20] Pham, K., F. Sacirbegovic, and S.M. Russell. Polarized cells, polarized views: asymmetric cell division in hematopoietic cells. Front Immunol. 5: 26, 2014.

[21] Doe, C.Q. and B. Bowerman. Asymmetric cell division: fly neuroblast meets worm zygote. Current Opinion in Cell Biology. 13: 68-75, 2001.

[22] Rocheleau, C.E., W.D. Downs, R. Lin, C. Wittmann, Y. Bei, Y.-H. Cha, M. Ali, J.R. Priess, and C.C. Mello. Wnt Signaling and an APC-Related Gene Specify Endoderm in Early C. elegans Embryos. Cell. 90: 707-716, 1997.

[23] Götz, M. and W.B. Huttner. The cell biology of neurogenesis. Nature Reviews Molecular Cell Biology. 6: 777, 2005.

[24] Shen, Q., W. Zhong, Y.N. Jan, and S. Temple. Asymmetric Numb distribution is critical for asymmetric cell division of mouse cerebral cortical stem cells and neuroblasts. Development. 129: 4843-4853, 2002.

[25] Mascré, G., S. Dekoninck, B. Drogat, K.K. Youssef, S. Brohée, P.A. Sotiropoulou, B.D. Simons, and C. Blanpain. Distinct contribution of stem and progenitor cells to epidermal maintenance. Nature. 489: 257, 2012.

[26] Aragona, M., S. Dekoninck, S. Rulands, S. Lenglez, G. Mascré, B.D. Simons, and C. Blanpain. Defining stem cell dynamics and migration during wound healing in mouse skin epidermis. Nature Communications. 8: 14684, 2017.

[27] Ridley, A.J., M.A. Schwartz, K. Burridge, R.A. Firtel, M.H. Ginsberg, G. Borisy, J.T. Parsons, and A.R. Horwitz. Cell migration: integrating signals from front to back. Science. 302: 1704-9, 2003.

[28] Friedl, P. and D. Gilmour. Collective cell migration in morphogenesis, regeneration and cancer. Nat Rev Mol Cell Biol. 10: 445-57, 2009.

[29] Adams, J.M. and S. Cory. The Bcl-2 apoptotic switch in cancer development and therapy. Oncogene. 26: 1324-1337, 2007.

[30] Muller, P.A.J. and K.H. Vousden. p53 mutations in cancer. Nature Cell Biology. 15: 2, 2013.

[31] Stephens, P.J., C.D. Greenman, B. Fu, F. Yang, G.R. Bignell, L.J. Mudie, E.D. Pleasance, K.W. Lau, D. Beare, L.A. Stebbings, S. McLaren, M.-L. Lin, D.J. McBride, I. Varela, S. Nik-Zainal, C. Leroy, M. Jia, A. Menzies, A.P. Butler, J.W. Teague, M.A. Quail, J. Burton, H. Swerdlow, N.P. Carter, L.A. Morsberger, C. Iacobuzio-Donahue, G.A. Follows, A.R. Green, A.M. Flanagan, M.R. Stratton, P.A. Futreal, and P.J. Campbell. Massive Genomic Rearrangement Acquired in a Single Catastrophic Event during Cancer Development. Cell. 144: 27-40, 2011.

[32] Morrison, S.J. and J. Kimble. Asymmetric and symmetric stem-cell divisions in development and cancer. Nature. 441: 1068-74, 2006.

[33] Mukherjee, S., J. Kong, and D.J. Brat. Cancer stem cell division: when the rules of asymmetry are broken. Stem Cells Dev. 24: 405-16, 2015.

[34] Bajaj, J., B. Zimdahl, and T. Reya. Fearful symmetry: subversion of asymmetric division in cancer development and progression. Cancer Res. 75: 792-7, 2015.

[35] Yang, J., S.A. Mani, J.L. Donaher, S. Ramaswamy, R.A. Itzykson, C. Come, P. Savagner, I. Gitelman, A. Richardson, and R.A. Weinberg. Twist, a Master 
Regulator of Morphogenesis, Plays an Essential Role in Tumor Metastasis. Cell. 117: 927-939, 2004.

[36] Voulgari, A. and A. Pintzas. Epithelial-mesenchymal transition in cancer metastasis: mechanisms, markers and strategies to overcome drug resistance in the clinic. Biochim Biophys Acta. 1796: 75-90, 2009.

[37] Kang, Y. and J. Massagué. Epithelial-Mesenchymal Transitions: Twist in Development and Metastasis. Cell. 118: 277-279, 2004.

[38] Reymond, N., J.H. Im, R. Garg, F.M. Vega, B. Borda d'Agua, P. Riou, S. Cox, F. Valderrama, R.J. Muschel, and A.J. Ridley. Cdc42 promotes transendothelial migration of cancer cells through $\beta 1$ integrin. The Journal of Cell Biology. 199: 653-668, 2012.

[39] Liu, M., N. Lang, M. Qiu, F. Xu, Q. Li, Q. Tang, J. Chen, X. Chen, S. Zhang, Z. Liu, J. Zhou, Y. Zhu, Y. Deng, Y. Zheng, and F. Bi. miR-137 targets Cdc42 expression, induces cell cycle G1 arrest and inhibits invasion in colorectal cancer cells. International Journal of Cancer. 128: 1269-1279, 2011.

[40] Kamai, T., T. Yamanishi, H. Shirataki, K. Takagi, H. Asami, Y. Ito, and K.-I. Yoshida. Overexpression of RhoA, Rac1, and Cdc42 GTPases Is Associated with Progression in Testicular Cancer. Clinical Cancer Research. 10: 4799-4805, 2004.

[41] Arsenio, J., P.J. Metz, and J.T. Chang. Asymmetric Cell Division in T Lymphocyte Fate Diversification. Trends Immunol. 36: 670-683, 2015.

[42] Beckmann, J., S. Scheitza, P. Wernet, J.C. Fischer, and B. Giebel. Asymmetric cell division within the human hematopoietic stem and progenitor cell compartment: identification of asymmetrically segregating proteins. Blood. 109: 5494-5501, 2007.

[43] Duffy, K.R., C.J. Wellard, J.F. Markham, J.H.S. Zhou, R. Holmberg, E.D. Hawkins, J. Hasbold, M.R. Dowling, and P.D. Hodgkin. Activation-Induced B Cell Fates Are Selected by Intracellular Stochastic Competition. Science. 335: 338-341, 2012.

[44] Chang, J.T., V.R. Palanivel, I. Kinjyo, F. Schambach, A.M. Intlekofer, A. Banerjee, S.A. Longworth, K.E. Vinup, P. Mrass, J. Oliaro, N. Killeen, J.S. Orange, S.M. Russell, W. Weninger, and S.L. Reiner. Asymmetric T Lymphocyte Division in the Initiation of Adaptive Immune Responses. Science. 315: 16871691, 2007.

[45] Ciocca, M.L., B.E. Barnett, J.K. Burkhardt, J.T. Chang, and S.L. Reiner. Asymmetric memory $\mathrm{T}$ cell division in response to re-challenge. Journal of Immunology (Baltimore, Md. : 1950). 188: 4145-4148, 2012.

[46] Oliaro, J., V. Van Ham, F. Sacirbegovic, A. Pasam, Z.e. Bomzon, K. Pham, M.J. Ludford-Menting, N.J. Waterhouse, M. Bots, E.D. Hawkins, S.V. Watt, L.A. Cluse, C.J.P. Clarke, D.J. Izon, J.T. Chang, N. Thompson, M. Gu, R.W. Johnstone, M.J. Smyth, P.O. Humbert, S.L. Reiner, and S.M. Russell. Asymmetric Cell Division of T Cells upon Antigen Presentation Uses Multiple Conserved Mechanisms. The Journal of Immunology. 185: 367-375, 2010.

[47] Ludford-Menting, M.J., J. Oliaro, F. Sacirbegovic, E.T. Cheah, N. Pedersen, S.J. Thomas, A. Pasam, R. Iazzolino, L.E. Dow, N.J. Waterhouse, A. Murphy, S. Ellis, M.J. Smyth, M.H. Kershaw, P.K. Darcy, P.O. Humbert, and S.M. Russell. A network of PDZ-containing proteins regulates $\mathrm{T}$ cell polarity and morphology 
during migration and immunological synapse formation. Immunity. 22: 737-48, 2005.

[48] Li, Y. and K.A. Kilian. Bridging the Gap: From 2D Cell Culture to 3D Microengineered Extracellular Matrices. Advanced Healthcare Materials. 4: 2780-2796, 2015.

[49] Freida, D., S. Lecourt, A. Cras, V. Vanneaux, G. Letort, X. Gidrol, L. Guyon, J. Larghero, and M. Thery. Human bone marrow mesenchymal stem cells regulate biased DNA segregation in response to cell adhesion asymmetry. Cell Rep. 5: 601-10, 2013.

[50] Mahmud, G., C.J. Campbell, K.J.M. Bishop, Y.A. Komarova, O. Chaga, S. Soh, S. Huda, K. Kandere-Grzybowska, and B.A. Grzybowski. Directing cell motions on micropatterned ratchets. Nature Physics. 5: 606, 2009.

[51] Théry, M., V. Racine, M. Piel, A. Pépin, A. Dimitrov, Y. Chen, J.-B. Sibarita, and M. Bornens. Anisotropy of cell adhesive microenvironment governs cell internal organization and orientation of polarity. Proceedings of the National Academy of Sciences. 103: 19771-19776, 2006.

[52] Jiang, X., D.A. Bruzewicz, A.P. Wong, M. Piel, and G.M. Whitesides. Directing cell migration with asymmetric micropatterns. Proceedings of the National Academy of Sciences of the United States of America. 102: 975-978, 2005.

[53] Kushiro, K., S. Chang, and A.R. Asthagiri. Reprogramming directional cell motility by tuning micropattern features and cellular signals. Adv Mater. 22: 4516-9, 2010.

[54] Kumar, G., C.C. Co, and C.-C. Ho. Steering Cell Migration Using Microarray Amplification of Natural Directional Persistence. Langmuir : the ACS journal of surfaces and colloids. 27: 3803-3807, 2011.

[55] Peng, R., X. Yao, and J. Ding. Effect of cell anisotropy on differentiation of stem cells on micropatterned surfaces through the controlled single cell adhesion. Biomaterials. 32: 8048-57, 2011.

[56] Harris, G.M., M.E. Piroli, and E. Jabbarzadeh. Deconstructing the Effects of Matrix Elasticity and Geometry in Mesenchymal Stem Cell Lineage Commitment. Advanced Functional Materials. 24: 2396-2403, 2014.

[57] McWhorter, F.Y., T. Wang, P. Nguyen, T. Chung, and W.F. Liu. Modulation of macrophage phenotype by cell shape. Proceedings of the National Academy of Sciences. 110: 17253-17258, 2013.

[58] Théry, M., A. Jiménez-Dalmaroni, V. Racine, M. Bornens, and F. Jülicher. Experimental and theoretical study of mitotic spindle orientation. Nature. 447: 493, 2007.

[59] Cheng, Q., G.M. Harris, M.-O. Blais, K. Rutledge, and E. Jabbarzadeh. Alignment of Carbon Nanotubes: An Approach to Modulate Cell Orientation and Asymmetry. Nano LIFE. 4: 1450002, 2014.

[60] Rothrauff, B.B., B.B. Lauro, G. Yang, R.E. Debski, V. Musahl, and R.S. Tuan. Braided and Stacked Electrospun Nanofibrous Scaffolds for Tendon and Ligament Tissue Engineering. Tissue Engineering Part A. 23: 378-389, 2017.

[61] Shamirzaei Jeshvaghani, E., L. Ghasemi-Mobarakeh, R. Mansurnezhad, F. Ajalloueian, M. Kharaziha, M. Dinari, M. Sami Jokandan, and S. Chronakis Ioannis. Fabrication, characterization, and biocompatibility assessment of a novel 
elastomeric nanofibrous scaffold: A potential scaffold for soft tissue engineering. Journal of Biomedical Materials Research Part B: Applied Biomaterials. 0, 2017. [62] Nie, W., C. Peng, X. Zhou, L. Chen, W. Wang, Y. Zhang, P.X. Ma, and C. He. Three-dimensional porous scaffold by self-assembly of reduced graphene oxide and nano-hydroxyapatite composites for bone tissue engineering. Carbon. 116: 325-337, 2017.

[63] Graziano, A., R. d'Aquino, M.G. Cusella-De Angelis, F. De Francesco, A. Giordano, G. Laino, A. Piattelli, T. Traini, A. De Rosa, and G. Papaccio. Scaffold's surface geometry significantly affects human stem cell bone tissue engineering. J Cell Physiol. 214: 166-72, 2008.

[64] Wang, Y., D.B. Gunasekara, M.I. Reed, M. DiSalvo, S.J. Bultman, C.E. Sims, S.T. Magness, and N.L. Allbritton. A microengineered collagen scaffold for generating a polarized crypt-villus architecture of human small intestinal epithelium. Biomaterials. 128: 44-55, 2017.

[65] Schultz, K.M., K.A. Kyburz, and K.S. Anseth. Measuring dynamic cell-material interactions and remodeling during 3D human mesenchymal stem cell migration in hydrogels. Proc Natl Acad Sci U S A. 112: E3757-64, 2015.

[66] Shamloo, A., N. Ma, M.M. Poo, L.L. Sohn, and S.C. Heilshorn. Endothelial cell polarization and chemotaxis in a microfluidic device. Lab Chip. 8: 1292-9, 2008.

[67] Huang, Y., B. Agrawal, D. Sun, J.S. Kuo, and J.C. Williams. Microfluidics-based devices: New tools for studying cancer and cancer stem cell migration. Biomicrofluidics. 5: 013412, 2011.

[68] Eslami Amirabadi, H., S. SahebAli, J.P. Frimat, R. Luttge, and J.M.J. den Toonder. A novel method to understand tumor cell invasion: integrating extracellular matrix mimicking layers in microfluidic chips by "selective curing". Biomedical Microdevices. 19: 92, 2017.

[69] Irimia, D. and M. Toner. Spontaneous migration of cancer cells under conditions of mechanical confinement(). Integrative biology : quantitative biosciences from nano to macro. 1: 506-512, 2009.

[70] Venugopal, B., P. Mogha, J. Dhawan, and A. Majumder. Cell density overrides the effect of substrate stiffness on human mesenchymal stem cells' morphology and proliferation. Biomater Sci, 2018.

[71] Chen, C.S., M. Mrksich, S. Huang, G.M. Whitesides, and D.E. Ingber. Geometric control of cell life and death. Science. 276: 1425-8, 1997.

[72] Chen, C.S., M. Mrksich, S. Huang, G.M. Whitesides, and D.E. Ingber. Micropatterned surfaces for control of cell shape, position, and function. Biotechnol Prog. 14: 356-63, 1998.

[73] Zhong, Y. and B. Ji. Impact of cell shape on cell migration behavior on elastic substrate. Biofabrication. 5: 015011, 2013.

[74] Thery, M. Micropatterning as a tool to decipher cell morphogenesis and functions. J Cell Sci. 123: 4201-13, 2010.

[75] Mooney, D., L. Hansen, J. Vacanti, R. Langer, S. Farmer, and D. Ingber. Switching from differentiation to growth in hepatocytes: control by extracellular matrix. J Cell Physiol. 151: 497-505, 1992.

[76] Zhang, D. and K.A. Kilian. The effect of mesenchymal stem cell shape on the maintenance of multipotency. Biomaterials. 34: 3962-9, 2013. 
[77] Kilian, K.A., B. Bugarija, B.T. Lahn, and M. Mrksich. Geometric cues for directing the differentiation of mesenchymal stem cells. Proc Natl Acad Sci U S A. 107: 4872-7, 2010.

[78] McBeath, R., D.M. Pirone, C.M. Nelson, K. Bhadriraju, and C.S. Chen. Cell shape, cytoskeletal tension, and RhoA regulate stem cell lineage commitment. Developmental cell. 6: 483-495, 2004.

[79] Winer, J.P., P.A. Janmey, M.E. McCormick, and M. Funaki. Bone marrowderived human mesenchymal stem cells become quiescent on soft substrates but remain responsive to chemical or mechanical stimuli. Tissue Eng Part A. 15: 14754, 2009.

[80] Engler, A.J., S. Sen, H.L. Sweeney, and D.E. Discher. Matrix elasticity directs stem cell lineage specification. Cell. 126: 677-89, 2006.

[81] Guilak, F., D.M. Cohen, B.T. Estes, J.M. Gimble, W. Liedtke, and C.S. Chen. Control of stem cell fate by physical interactions with the extracellular matrix. Cell Stem Cell. 5: 17-26, 2009.

[82] Lee, J., A.A. Abdeen, and K.A. Kilian. Rewiring mesenchymal stem cell lineage specification by switching the biophysical microenvironment. Scientific reports. 4, 2014.

[83] Harris, G.M., T. Shazly, and E. Jabbarzadeh. Deciphering the Combinatorial Roles of Geometric, Mechanical, and Adhesion Cues in Regulation of Cell Spreading. PLoS ONE. 8: e81113, 2013.

[84] Rowlands, A.S., P.A. George, and J.J. Cooper-White. Directing osteogenic and myogenic differentiation of MSCs: interplay of stiffness and adhesive ligand presentation. Am J Physiol Cell Physiol. 295: C1037-44, 2008.

[85] Drubin, D.G. and W.J. Nelson. Origins of cell polarity. Cell. 84: 335-44, 1996.

[86] Lee, M. and V. Vasioukhin. Cell polarity and cancer--cell and tissue polarity as a non-canonical tumor suppressor. J Cell Sci. 121: 1141-50, 2008.

[87] Krtolica, A., O. Genbacev, C. Escobedo, T. Zdravkovic, A. Nordstrom, D. Vabuena, A. Nath, C. Simon, K. Mostov, and S.J. Fisher. Disruption of apicalbasal polarity of human embryonic stem cells enhances hematoendothelial differentiation. Stem Cells. 25: 2215-23, 2007.

[88] Lechler, T. and E. Fuchs. Asymmetric cell divisions promote stratification and differentiation of mammalian skin. Nature. 437: 275-80, 2005.

[89] Thery, M. and M. Bornens. Cell shape and cell division. Curr Opin Cell Biol. 18: 648-57, 2006.

[90] Thery, M., V. Racine, M. Piel, A. Pepin, A. Dimitrov, Y. Chen, J.B. Sibarita, and M. Bornens. Anisotropy of cell adhesive microenvironment governs cell internal organization and orientation of polarity. Proc Natl Acad Sci U S A. 103: 19771-6, 2006.

[91] Yeaman, C., K.K. Grindstaff, and W.J. Nelson. New perspectives on mechanisms involved in generating epithelial cell polarity. Physiol Rev. 79: 73-98, 1999.

[92] Harris, G.M., M.E. Piroli, and E. Jabbarzadeh. Deconstructing the Effects of Matrix Elasticity and Geometry in Mesenchymal Stem Cell Lineage Commitment. Adv Funct Mater. 24: 2396-2403, 2014.

[93] Lee, J., A.A. Abdeen, T.H. Huang, and K.A. Kilian. Controlling cell geometry on substrates of variable stiffness can tune the degree of osteogenesis in human 
mesenchymal stem cells. Journal of the Mechanical Behavior of Biomedical Materials. 38: 209-218, 2014.

[94] Peng, R., X. Yao, B. Cao, J. Tang, and J. Ding. The effect of culture conditions on the adipogenic and osteogenic inductions of mesenchymal stem cells on micropatterned surfaces. Biomaterials. 33: 6008-19, 2012.

[95] Walsh, T., H. Shahin, T. Elkan-Miller, M.K. Lee, A.M. Thornton, W. Roeb, A. Abu Rayyan, S. Loulus, K.B. Avraham, M.-C. King, and M. Kanaan. Whole Exome Sequencing and Homozygosity Mapping Identify Mutation in the Cell Polarity Protein GPSM2 as the Cause of Nonsyndromic Hearing Loss DFNB82. The American Journal of Human Genetics. 87: 90-94, 2010.

[96] Kaushik, R., F. Yu, W. Chia, X. Yang, and S. Bahri. Subcellular Localization of LGN During Mitosis: Evidence for Its Cortical Localization in Mitotic Cell Culture Systems and Its Requirement for Normal Cell Cycle Progression. Molecular Biology of the Cell. 14: 3144-3155, 2003.

[97] Wright, C.E., E.J. Kushner, Q. Du, and V.L. Bautch. LGN Directs Interphase Endothelial Cell Behavior via the Microtubule Network. PLoS One. 10: e0138763, 2015.

[98] Konno, D., G. Shioi, A. Shitamukai, A. Mori, H. Kiyonari, T. Miyata, and F. Matsuzaki. Neuroepithelial progenitors undergo LGN-dependent planar divisions to maintain self-renewability during mammalian neurogenesis. Nat Cell Biol. 10: 93-101, 2008.

[99] Kamakura, S., M. Nomura, J. Hayase, Y. Iwakiri, A. Nishikimi, R. Takayanagi, Y. Fukui, and H. Sumimoto. The cell polarity protein mInsc regulates neutrophil chemotaxis via a noncanonical G protein signaling pathway. Dev Cell. 26: 292302, 2013.

[100] Kimura, K., M. Ito, M. Amano, K. Chihara, Y. Fukata, M. Nakafuku, B. Yamamori, J. Feng, T. Nakano, K. Okawa, A. Iwamatsu, and K. Kaibuchi. Regulation of myosin phosphatase by Rho and Rho-associated kinase (Rhokinase). Science. 273: 245-8, 1996.

[101] Ishizaki, T., M. Uehata, I. Tamechika, J. Keel, K. Nonomura, M. Maekawa, and S. Narumiya. Pharmacological properties of Y-27632, a specific inhibitor of rhoassociated kinases. Mol Pharmacol. 57: 976-83, 2000.

[102] Vasquez, R.J., B. Howell, A.M. Yvon, P. Wadsworth, and L. Cassimeris. Nanomolar concentrations of nocodazole alter microtubule dynamic instability in vivo and in vitro. Mol Biol Cell. 8: 973-85, 1997.

[103] Chang, Y.C., P. Nalbant, J. Birkenfeld, Z.F. Chang, and G.M. Bokoch. GEF-H1 couples nocodazole-induced microtubule disassembly to cell contractility via RhoA. Mol Biol Cell. 19: 2147-53, 2008.

[104] Kilian, K.A. and M. Mrksich. Directing stem cell fate by controlling the affinity and density of ligand-receptor interactions at the biomaterials interface. Angew Chem Int Ed Engl. 51: 4891-5, 2012.

[105] Nelson, C.M. and C.S. Chen. Cell-cell signaling by direct contact increases cell proliferation via a PI3K-dependent signal. FEBS Lett. 514: 238-42, 2002.

[106] Simons, M. and M. Mlodzik. Planar Cell Polarity Signaling: From Fly Development to Human Disease. Annual review of genetics. 42: 517, 2008. 
[107] Wodarz, A. and I. Näthke. Cell polarity in development and cancer. Nature Cell Biology. 9: 1016, 2007.

[108] Ben-Yair, R., N. Kahane, and C. Kalcheim. LGN-dependent orientation of cell divisions in the dermomyotome controls lineage segregation into muscle and dermis. Development. 138: 4155-66, 2011.

[109] Thery, M., A. Jimenez-Dalmaroni, V. Racine, M. Bornens, and F. Julicher. Experimental and theoretical study of mitotic spindle orientation. Nature. 447: 493-496, 2007.

[110] James, A.W. Review of Signaling Pathways Governing MSC Osteogenic and Adipogenic Differentiation. Scientifica (Cairo). 2013: 684736, 2013.

[111] Ling, L., V. Nurcombe, and S.M. Cool. Wnt signaling controls the fate of mesenchymal stem cells. Gene. 433: 1-7, 2009.

[112] Wozniak, M.A. and C.S. Chen. Mechanotransduction in development: a growing role for contractility. Nat Rev Mol Cell Biol. 10: 34-43, 2009. 


\section{APPENDIX A: PERMISSION TO REPRINT}

This Agreement between University of South Carolina -- Maria Piroli ("You") and Springer

Nature ("Springer Nature") consists of your license details and the terms and conditions provided by Springer Nature and Copyright Clearance Center.

License Number 4320431314136

License date Apr 01, 2018

Licensed Content Publisher Springer Nature

Licensed Content Publication Annals of Biomedical Engineering

Licensed Content Title Matrix Stiffness Modulates Mesenchymal Stem Cell Sensitivity to

Geometric Asymmetry Signals

Licensed Content Author Maria E. Piroli, Ehsan Jabbarzadeh

Licensed Content Date Jan 1, 2018

Type of Use Thesis/Dissertation

Requestor type academic/university or research institute

Format electronic

Portion full article/chapter

Will you be translating? no

Circulation/distribution $<501$

Author of this Springer

Nature content

yes

Title Matrix stiffness modulates mesenchymal stem cell sensitivity to

geometric asymmetry signals

Instructor name Ehsan Jabbarzadeh

Institution name University of South Carolina

Expected presentation date Apr 2018

Requestor Location University of South Carolina

301 Main St. College of Engi neering

COLUMBIA, SC 29201

United States

Attn: Maria Pi roli

Billing Type Invoice

Billing Address University of South Carolina

301 Main St. College of Engi neering

COLUMBIA, SC 29201

United States

Attn: Maria Pi roli

Total 0.00 USD

Terms and Conditions

Springer Nature Terms and Conditions for RightsLink Permissions 4/10/2018 RightsLink Printable License

https://s100.copyright.com/CustomerAdmin/PLF.jsp?ref=027500f9-9852-4610-99f1-f728979647d3 2/3

Springer Customer Service Centre GmbH (the Licensor) hereby grants you a nonexclusive,

world-wide licence to reproduce the material and for the purpose and

requirements specified in the attached copy of your order form, and for no other use, subject to the conditions below: 
1. The Licensor warrants that it has, to the best of its knowledge, the rights to license reuse of this material. However, you should ensure that the material you are requesting is original to the Licensor and does not carry the copyright of another entity (as credited in the published version).

If the credit line on any part of the material you have requested indicates that it was reprinted or adapted with permission from another source, then you should also seek permission from that source to reuse the material.

2. Where print only permission has been granted for a fee, separate permission must be obtained for any additional electronic re-use.

3. Permission granted free of charge for material in print is also usually granted for any electronic version of that work, provided that the material is incidental to your work as a whole and that the electronic version is essentially equivalent to, or substitutes for, the print version.

4. A licence for 'post on a website' is valid for 12 months from the licence date. This licence does not cover use of full text articles on websites.

5. Where 'reuse in a dissertation/thesis' has been selected the following terms apply: Print rights for up to 100 copies, electronic rights for use only on a personal website or institutional repository as defined by the Sherpa guideline (www.sherpa.ac.uk/romeo/). 6. Permission granted for books and journals is granted for the lifetime of the first edition and does not apply to second and subsequent editions (except where the first edition permission was granted free of charge or for signatories to the STM Permissions Guidelines http://www.stm-assoc.org/copyright-legal-affairs/permissions/permissions-guidelines/), and does not apply for editions in other languages unless additional translation rights have been granted separately in the licence.

7. Rights for additional components such as custom editions and derivatives require additional permission and may be subject to an additional fee. Please apply to Journalpermissions@springernature.com/bookpermissions@springernature.com for these rights.

8. The Licensor's permission must be acknowledged next to the licensed material in print. In electronic form, this acknowledgement must be visible at the same time as the figures/tables/illustrations or abstract, and must be hyperlinked to the journal/book's homepage. Our required acknowledgement format is in the Appendix below.

9. Use of the material for incidental promotional use, minor editing privileges (this does not include cropping, adapting, omitting material or any other changes that affect the meaning, intention or moral rights of the author) and copies for the disabled are permitted under this licence.

10. Minor adaptations of single figures (changes of format, colour and style) do not require the Licensor's approval. However, the adaptation should be credited as shown in Appendix below. 